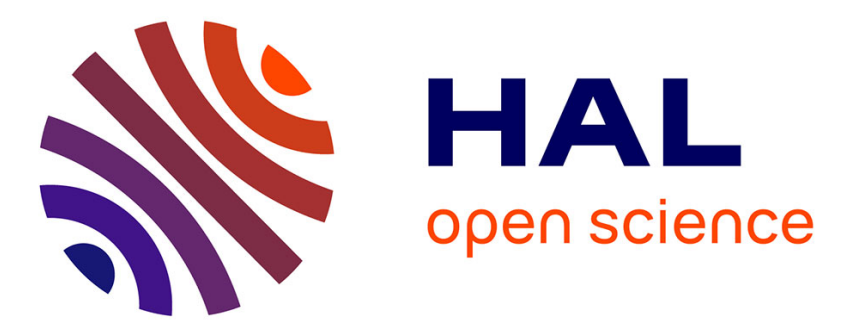

\title{
Seismo-ionospheric coupling appearing as equatorial electron density enhancements observed via DEMETER electron density measurements
}

K Ryu, E Lee, J.S. Chae, Michel Parrot, S Pulinets

\section{- To cite this version:}

K Ryu, E Lee, J.S. Chae, Michel Parrot, S Pulinets. Seismo-ionospheric coupling appearing as equatorial electron density enhancements observed via DEMETER electron density measurements. Journal of Geophysical Research Space Physics, 2014, 119, pp.8524-8542. 10.1002/2014JA020284 . insu01174160

HAL Id: insu-01174160

https://hal-insu.archives-ouvertes.fr/insu-01174160

Submitted on 21 Jul 2015

HAL is a multi-disciplinary open access archive for the deposit and dissemination of scientific research documents, whether they are published or not. The documents may come from teaching and research institutions in France or abroad, or from public or private research centers.
L'archive ouverte pluridisciplinaire $\mathbf{H A L}$, est destinée au dépôt et à la diffusion de documents scientifiques de niveau recherche, publiés ou non, émanant des établissements d'enseignement et de recherche français ou étrangers, des laboratoires publics ou privés. 


\section{Journal of Geophysical Research: Space Physics}

\author{
RESEARCH ARTICLE \\ 10.1002/2014JA020284 \\ Key Points: \\ - Statistical analyses on EIA enhance- \\ ments in DEMETER data and \\ seismic activities \\ - Significant cross correlation in \\ the region with minimal \\ longitudinal asymmetry \\ - Physical mechanisms to explain \\ the seismo-ionospheric \\ coupling discussed
}

Correspondence to:

K. Ryu,

kwangsun@kaist.ac.kr

\section{Citation:}

Ryu, K., E. Lee, J. S. Chae, M. Parrot, and S. Pulinets (2014), Seismo-ionospheric coupling appearing as equatorial electron density enhancements observed via DEMETER electron density measurements, J. Geophys. Res. Space Physics, 119, 8524-8542, doi:10.1002/2014JA020284.

Received 10 JUN 2014

Accepted 16 SEP 2014

Accepted article online 18 SEP 2014

Published online 9 OCT 2014

\section{Seismo-ionospheric coupling appearing as equatorial electron density enhancements observed via DEMETER electron density measurements}

\author{
K. Ryu' ', E. Lee ${ }^{2}$, J. S. Chae' ', M. Parrot ${ }^{3}$, and S. Pulinets ${ }^{4}$ \\ ${ }^{1}$ Satellite Technology Research Center, Korea Advanced Institute of Science and Technology, Daejeon, South Korea, \\ ${ }^{2}$ School of Space Research, Kyung Hee University, Yongin, South Korea, ${ }^{3}$ LPC2E/CNRS 3A, Orléans, France, ${ }^{4}$ Space \\ Research Institute, Russian Academy of Sciences, Moscow, Russia
}

\begin{abstract}
We report the processes and results of statistical analysis on the ionospheric electron density data measured by the Detection of Electro-Magnetic Emissions Transmitted from Earthquake Regions (DEMETER) satellite over a period of 6 years (2005-2010), in order to investigate the correlation between seismic activity and equatorial plasma density variations. To simplify the analysis, three equatorial regions with frequent earthquakes were selected and then one-dimensional time series analysis between the daily seismic activity indices and the equatorial ionization anomaly (EIA) intensity indices, which represent relative equatorial electron density increase, were performed for each region. The statistically significant values of the lagged cross-correlation function, particularly in the region with minimal effects of longitudinal asymmetry, indicate that some of the very large earthquakes with $M>5.0$ in the low-latitude region can accompany observable precursory and concurrent EIA enhancements, even though the seismic activity is not the most significant driver of the equatorial ionospheric evolution. The physical mechanisms of the seismo-ionospheric coupling is consistent with our observation, and the possibility of earthquake prediction using the EIA intensity variation is discussed.
\end{abstract}

\section{Introduction}

The equatorial ionization anomaly (EIA) is an important feature of the equatorial ionosphere. Since Appleton [1954] discovered the EIA, it has been explained that the formation of the EIA results from the diurnal variation of the zonal electric field and the interaction with the horizontal geomagnetic field at the equatorial region, which uplifts the plasma via an $\mathbf{E} \times \mathbf{B}$ drift [Anderson, 1981; Walker et al., 1994]. Electric fields and neutral winds, in addition to gravity, are the major drivers of low-latitude ionospheric dynamics [Kelley, 1989; Heelis, 2004]. The EIA feature related to the neutral winds is the longitudinal variations of the plasma density. The longitudinal plasma density pattern was firstly reported in observations by the Russian satellite Intercosmos-19 [Kochenova, 1987]. Wave number-N longitudinal structure [Bankov et al., 2009] implies the equally spaced peaks in electron density or total electron content (TEC) in longitudinal direction. For example, WN4 structure means there exist four quasi-periodic longitudinal peaks in the global distribution of the ionospheric density. The first attempt to generalize the longitudinal structure according to the local time and altitude was made by Benkova et al. [1990]. Depuev and Pulinets [2004] attempted to include the longitudinal dependencies in a global empirical model of the ionosphere. Sagawa et al. [2005] identified the formation of WN4 patterns in the $F$ region from the optical observation using the far ultraviolet imager on board the IMAGE satellite. Immel et al. [2006] and England et al. [2006] attributed the generation of the observed WN3 and WN4 plasma density patterns to the diurnal zonal tides that can modulate the $E$ region dynamo electric field.

In the context of the EIA variation related to the seismo-ionospheric coupling, Pulinets and Lengen'ka [2002] reported longitudinal asymmetry in relation to the impending earthquake epicenter and distortion of the EIA shape observed by the Intercosmos-19 topside sounder. Distortions in the longitudinal distribution of the $f_{o} F_{2}$ measured by the Intercosmos-19 two days before and on the day of the $M 7.3$ earthquakes in the New Guinea region were reported by Pulinets [2012]. Oyama et al. [2011] reported reductions in the ion density in DE-2 satellite observations around the M7.1 Chilean earthquake of October 1981. These changes in ion density exhibited characteristic latitudinal features similar to the ElA. Recently, Ryu et al. [2014] reported seismically intensified EIA features related to the M8.7 northern Sumatra earthquake of March 2005 and 
the M8.0 Pisco earthquake of August 2007. In parallel, theoretical and numerical studies were conducted [Namgaladze et al., 2009; Kuo et al., 2011; Klimenko et al., 2012] in order to explain the underlying mechanisms of the plasma drift and the consequent change in the ionospheric plasma density caused by the seismo-ionosphere coupling.

In this study, we introduce the processes and results of rigorous analysis on the 6 year long Detection of Electro-Magnetic Emissions Transmitted from Earthquake Regions (DEMETER) ionospheric observations of the plasma density in order to investigate whether a statistically significant correlation exists between the EIA intensity variation and seismic activity in the equatorial region. In the process of defining the time series of the EIA intensity, the seasonal and longitudinal density variations were subtracted and the space weather effects were also eliminated in order to improve the reliability of the analysis. Based on the statistical analysis, the physical mechanism of the seismo-ionospheric coupling that explain the results and the possibility of earthquake predictions are discussed.

\section{Satellite Observations and Data Processing}

\subsection{Satellite Observations}

The DEMETER satellite, launched on 29 June 2004, had a dedicated mission of studying the disturbances of the ionosphere due to seismo-electromagnetic effects [Parrot et al., 2006]. The official science mission was ended on 9 December 2010. The DEMETER satellite continuously collected data about the ionospheric plasma and electromagnetic waves in a Sun-synchronous orbit at an altitude of $710 \mathrm{~km}$ at the time of the launch. The orbit was lowered to $660 \mathrm{~km}$ in December 2005, without changing the ascending node. This made it suitable for studying global ionospheric disturbances at fixed local times centered around 10:30 LT (daytime) and 22:30 LT (nighttime).

Among the various scientific instruments including the Langmuir probe (ISL: Instrument Sonde de Langmuir) [Lebreton et al., 2006] and the retarding potential analyzer (Instrument d'Analyse du Plasma) [Berthelier et al., 2006], which were dedicated to monitoring ionospheric parameters, we focused on the measurement data of the ISL in order to parameterize the EIA strength. The ISL measured in situ ionospheric parameters including the electron density and temperature. Zhang [2014] pointed out that the relative variation in $T_{e}$ and $N_{e}$ measured by the ISL instrument ought to be credible, while the absolute values of the electron density and temperature may not be accurately determined due to the photoelectron contamination. Kakinami et al. [2013] reported that DEMETER $N_{e}$ is lower than that expected from observations by CHAMP and Gravity Recovery and Climate Experiment, but their altitudes were different. They also remarked that relative variations and averaged behavior are valid for scientific analysis, while the absolute values are less reliable.

The DEMETER ionospheric data were obtained via the CDPP (Centre de Données de la Physique des Plasmas) operated by Centre National d'Etudes Spatiales. We utilized the Level 1 processed data [Lagoutte et al., 2006], which contain the calibrated physical values derived from the raw instrumental data. The ISL data were captured in the survey mode and burst mode [Cussac et al., 2006] with different sampling rates for detailed observations around the region with the frequent earthquake occurrences. For our analyses, data files were combined in order to prepare a seamless data stream during the period of interest.

The ISL instrument was operated from July 2004 to December 2010. During the early stage, mostly in 2004 (from July to December), the ISL was operated in the engineering test mode with varying sweep voltages and frequencies, while it provided stable measurement data afterward. We utilized the ISL electron density measurements obtained over 6 years from 2005 to near the end of 2010 in our statistical study, except some periods when the satellite was in the safe mode.

The DEMETER satellite was operated in a Sun-synchronous orbit so that the night passes and day passes could be clearly separated according to the local time of observation. Because we focused on the ElA phenomena that occurred in the equatorial region during the daytime, only the daytime data were filtered and used in the analysis.

\subsection{Definition of the Normalized Equatorial Plasma Density for Indexing the EIA Strength} By definition, the EIA refers to the daytime latitudinal distribution of the $F_{2}$ layer ion concentration at low-geomagnetic latitudes characterized by a trough at the magnetic dip equator that is flanked by two crests in the northern and southern sides of the dip equator at approximately $\pm 15-20^{\circ}$ magnetic latitude. 


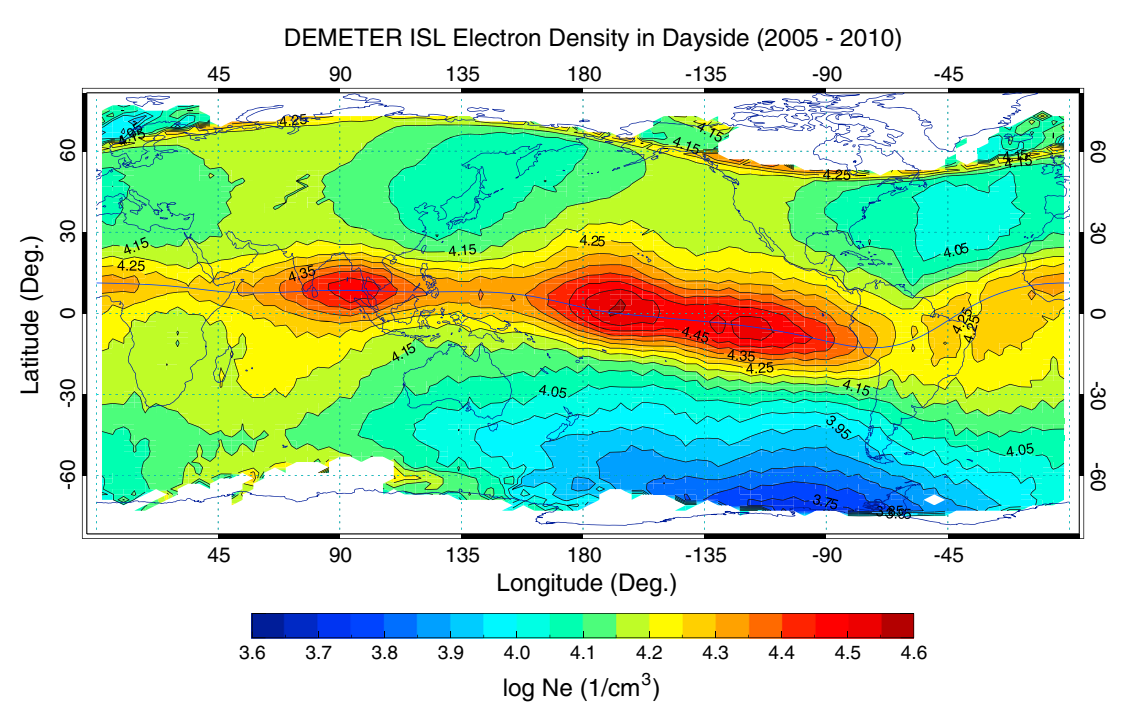

Figure 1. The global map of the electron density for the daytime measured by the ISL instrument. The contour was drawn in logarithmic scale of the $N_{e}$ based on the averaged values of the entire mission of DEMETER (2005-2010). The blue curve along the equator region presents the geomagnetic dip equator.

There have been efforts to quantify the strength and morphology of the EIA from the observed physical parameters. Mendillo et al. [2000] defined a strength index $\left(I_{S}\right)$ and asymmetry index $\left(I_{a}\right)$ as follows: $I_{s}=(N+S) / E$ and $I_{a}=(N-S) /((N+S) / 2)$, where $N, S$, and $E$ represent the total electron content (TEC) at the north and south crests, and at the equator trough, respectively. The crest asymmetry, with the local winter crest usually higher than the local summer one, is attributed to the cross-equatorial wind plasma transport [Rishbeth, 1977; Mendillo et al., 2005].

Later, Stolle et al. [2008] defined the crest-to-trough ratio analogous to the strength index [Mendillo et al., 2000] through substituting the TEC with the electron density measured by the CHAMP satellite [Lühr et al., 2012]. In addition, they defined the crest $L$ value of the flux tube as a measure of the altitude-independent EIA width. It is already known that the latitudinal profile of the EIA varies according to the satellite altitude. At the altitude of the DEMETER satellite $(710 \mathrm{~km}$ at the time of the launch and lowered to $660 \mathrm{~km}$ later) where the uplifted plasma begins to bifurcate along the geomagnetic field lines, the latitudinal profiles of the electron density did not exhibit a clear "crest-trough" structure, in opposite to observations of the CHAMP satellite with altitude less than $400 \mathrm{~km}$.

A similar case to that of the DEMETER satellite is Republic of China Satellite-1 (ROCSAT-1), which had a circular orbit at a mean altitude of $600 \mathrm{~km}$ with an orbital inclination of $35^{\circ}$. Kil et al. [2008] studied the EIA variation according to the season, longitude, and local time, with the equatorial plasma density measured by ROCSAT-1 normalized using the longitudinal mean density. For the DMSP satellites [Coley et al., 2010], which have Sun-synchronous orbits at a mean altitude of $840 \mathrm{~km}$, the EIA features were not observed during quiet conditions. During geomagnetic storms, ionosphere can inflate and equatorial anomaly can reach high altitude.

Figure 1 shows the global map of the electron density measured by ISL for the daytime (10:30 LT) during the entire mission of DEMETER. The contour map was derived by averaging the electron density with resolutions of $4^{\circ}$ and $2^{\circ}$ in longitude and latitude directions. The electron density is higher in the geomagnetic equator region than in the midlatitude region, and the longitudinal structure appears along the geomagnetic equator region. The detailed description on the behavior of the electron density measured by ISL according to the season and solar cycle can be found in the studies of Zhang et al. [2013] and Zhang [2014]. It is clear that only one peak region exists near the equator, in general, so the EIA intensity index derived using two density peaks in the Northern and Southern Hemispheres is not applicable to the altitude and local time of DEMETER during normal conditions.

In this study, the strength of the EIA is represented as the equatorial plasma density normalized by the midlatitude density, which is similar to the data presented by Kil et al. [2008] where they normalized the 

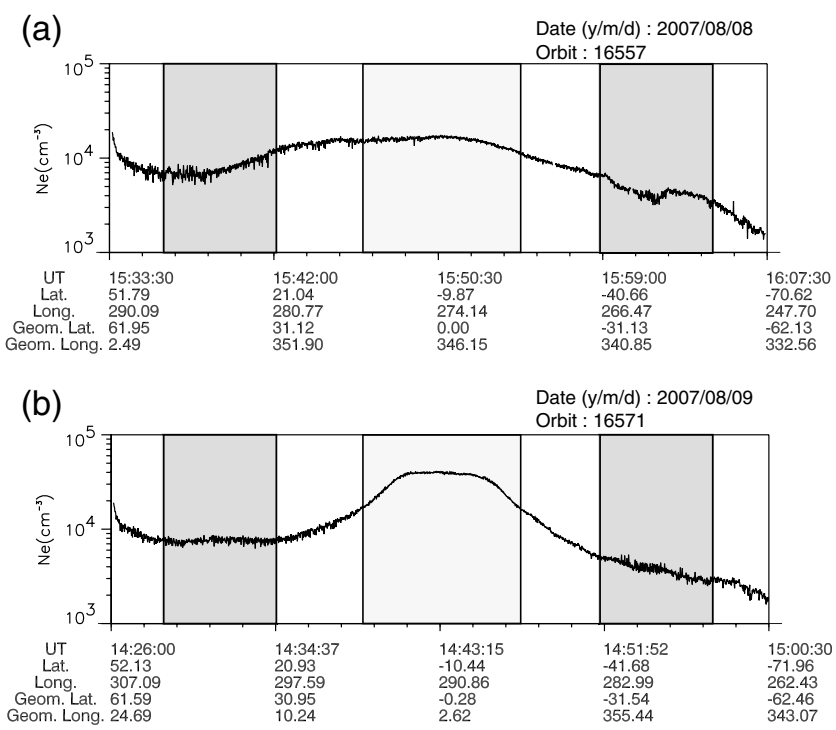

Figure 2. Examples of the electron density profiles measured by DEMETER: (a) Orbit 16557 on 8 August 2007 with nominal EIA enhancements and (b) Orbit 16571 on 9 August 2007 with enhanced equatorial plasma density. The dark grey boxes indicate the midlatitude (geomagnetic latitude: $30^{\circ}-50^{\circ} \mathrm{S}$ and $30^{\circ}-50^{\circ} \mathrm{N}$ ), while the light grey box indicates the equatorial region (geomagnetic latitude: $15^{\circ} \mathrm{S}-15^{\circ} \mathrm{N}$ ). equatorial plasma density using the longitudinal mean density. The normalized equatorial plasma density (NEPD) is defined as the ratio of the averaged $N_{e}$ in the region whose geomagnetic latitude is within $\pm 15^{\circ}$ with respect to the averaged midlatitude $N_{e}\left(30^{\circ}-50^{\circ} \mathrm{S}\right.$ and $30^{\circ}-50^{\circ} \mathrm{N}$ in the geomagnetic latitude), as NEPD = $N_{e}$ (equatorial) $/ N_{e}$ (midlatitude). In short, the NEPD is an index of EIA strength applicable to the DEMETER altitude and above.

The physical insight and the reason for defining the NEPD index can be found also in the plasma frequency (proportional to the square root of electron density) profile from the Sheffield University Plasmasphere-lonosphere Model runs introduced by Batista et al. [2011]. According to their results, the electron density shows clear crest-trough structure at the altitude of CHAMP (350 450 km), so that the methodology

and indexes defined for TEC analyses can be directly applied as in the work by Stolle et al. [2008]. Meanwhile, at the altitude of DEMETER (650-720 km) the EIA feature is changed to a bump-like profile instead of the crest-trough structure, so that the already created indexes which assume the clear crest-trough density profiles cannot be used. The usefulness of the NEPD in studying the seismo-ionospheric coupling analysis was already demonstrated by Ryu et al. [2014].

Figure 2 demonstrates how the NEPD was defined according to the $N_{e}$ profile measured by the ISL instrument. The $N_{e}$ profiles of successive days in August 2007, when the satellite passed similar longitudes, are presented with overlaid blocks that represent the above-defined equatorial and midlatitude regions. The two profiles exhibit clear differences because the electron density above the equatorial region along the Orbit 16571 (Figure 2b) was increased compared with that of the previous day (Orbit 16557 in Figure 2a). The NEPD values, which were derived as described above, were 1.7 and 4.1 for Orbit 16557 and Orbit 16571 , respectively, which implies that using the NEPD to quantify the EIA strength is appropriate at the DEMETER altitude.

\subsection{Geometry of the Equatorial Earthquake Occurrence}

We investigated the EIA variation on the assumption that the EIA can be affected by earthquakes that occur in the equatorial region through the seismo-ionospheric coupling processes. In practice, it would be much easier to separate the spatial and temporal correlations of the variables, otherwise the analysis becomes too complicated. In order to investigate the possibility of reducing the calculational complexity, the distribution of earthquakes during the study period (2005-2010) was derived from the Preliminary Determinations of Epicenters catalog of earthquakes provided by the U.S. Geological Survey-National Earthquake Information Center (USGS-NEIC) (http://earthquake.usgs.gov/regional/neic).

The distribution of the earthquakes that occurred during the studied period is presented in Figure 3 . The black dots in Figure 3a indicate the positions of the earthquakes with magnitudes larger than 5.0 that were chosen for the sake of the simplicity. However, the number of the earthquakes is enough to show the global distribution of the seismic activity. The apparent feature in the earthquake distribution is that a large number of earthquakes occurred along the "Ring of Fire" located around the perimeter of the Pacific Ocean. The next conspicuous feature is that many large earthquakes occurred in the Indian Ocean and the western coast of the Sumatra Islands. 
(a)

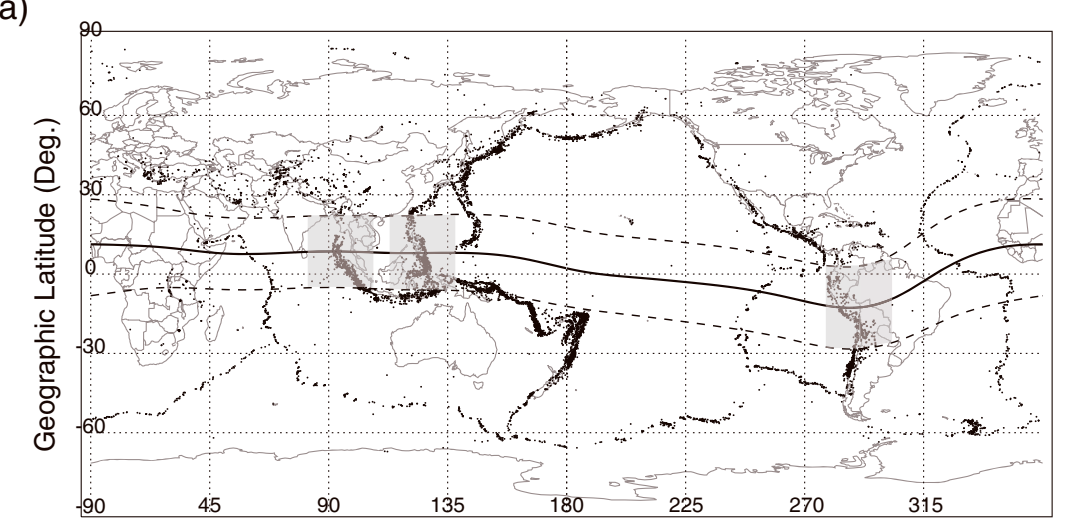

(b)

Geographic Longitude (Deg.)

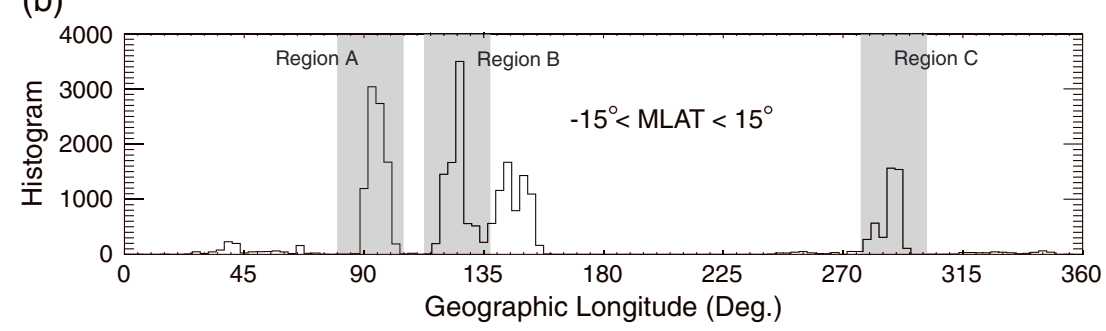

Figure 3. (a) The spatial distribution (black dots) of large earthquakes $(M>5.0)$ that occurred during the study period (2005-2010) on the world map. The solid and dashed curves represent the geomagnetic equator and $\pm 15^{\circ}$ latitude positions, respectively. (b) Histograms of earthquakes $(M>3.0)$ during the study period when the geomagnetic latitude was limited within $\pm 15^{\circ}$.

In order to quantify the distribution, the histogram of the earthquakes with magnitudes larger than 3.0 were derived according to the geographic longitude. Because the possible correlation of the earthquake to the EIA is being investigated, the geomagnetic latitude of the earthquake occurrence was limited within $\pm 15^{\circ}$ as shown in Figure 3b. Three regions with frequent earthquake occurrences depicted appear in the histograms; these are indicated using shadowed boxes.

One of the most frequent earthquake occurrence regions is located at $90^{\circ} \mathrm{E}-100^{\circ} \mathrm{E}$ longitude. This region is the Sumatra tectonic collision zone called the Sumatra Arc, which is oriented along the northwest to southeast direction [Hayes et al., 2013] and is designated as Region A.

The most frequent earthquake occurrence region, designated as Region $\mathrm{B}$, is at $120^{\circ} \mathrm{E}-130^{\circ} \mathrm{E}$ longitude. This region is the western part of the "New Guinea and vicinity" seismic zone where 22 earthquakes with magnitudes larger than 7.5 have occurred since 1900 [Benz et al., 2011].

The third frequent earthquake region is located at $285^{\circ} \mathrm{E}-295^{\circ} \mathrm{E}$, where the geomagnetic equatorial region coincides with the Nazca Plate and South America seismic zone [Rhea et al., 2010]; this region is designated as Region C. If the geomagnetic latitude range of the epicenters is extended to $\pm 20^{\circ}$ or more, the Nazca Plate and South America seismic zone would become the most frequent earthquake longitudinal region reaching almost 6000 earthquakes with magnitude of 3.0 or more within the 6 year study period.

Before beginning the statistical analysis according to the frequent earthquake regions defined above, the seasonal and longitudinal variations of the EIA strength (NEPD) were derived in order to separate the possible seismo-ionospheric coupling effects from the seasonal, longitudinal, and local time variations as well as the solar activity dependence [Liu et al., 2007]. Then, the time series analysis was executed for the frequent earthquake regions.

\section{Results}

\subsection{Seasonal and Longitudinal Variations of the NEPD}

When the stable observation of the DEMETER satellite began in 2005, it was the middle of the declining phase of Solar Cycle 23. The solar minimum that represents the start of the next solar cycle (Cycle 24) 
occurred in December 2008. The number of sunspots remained under 40, and the $F_{10.7}$ radio flux was less than $100 \mathrm{sfu}$ (solar flux units; $1 \mathrm{sfu}=10^{-22} \mathrm{~W} \mathrm{~m}^{-2} \mathrm{~Hz}^{-1}$ ) throughout the 6 year study period. This implies that the effects of the solar activity on the ionosphere were relatively low.

The global map of the electron density for the daytime was introduced by Kakinami et al. [2011], and the seasonal and longitudinal behavior was discussed in the context of longitudinal wave structure. As it is seen that seasonal and longitudinal dependences exist in the EIA, it is important to investigate whether such variations also appear in the NEPD. The results can be used as references from which the deviation caused by the possible seismo-ionospheric coupling or other unknown anomalies can appear. In short, the quickly changing seismic effect might be distinguished from slowly changing seasonal and longitudinal behavior. As seen in the later analysis, the NEPD, which is defined for every orbit in the dayside, changes abruptly in spatial and temporal scales; therefore, it was convenient to adjust the sampling size in the spatial and temporal coordinates in order that it was sufficiently large to smooth out these peaky changes.

Because the DEMETER satellite had a Sun-synchronous orbit, it generated dayside electron density profiles in the ascending nodes at quasi-constant local times. The longitude at which the satellite passed the equator was used as the spatial reference coordinate. The longitude of the equatorial pass proceeded approximately $25^{\circ}$ to the west every orbit, and an NEPD value is derived from each orbit pass in the dayside. If a sampling size of $6^{\circ}$ in longitudinal coordinate is used, it would require approximately 4-5 days to secure at least one NEPD data in every pixel in the longitudinal direction. Considering this, we defined $60 \times 60$ grids in the time and longitudinal coordinates, which were empirically determined to get rid of noisy pixels. That is, the pixel in the time direction had a pixel size of 365/60 days and that in the longitudinal direction had a pixel size of $360^{\circ} / 60\left(6^{\circ}\right)$.

The derivation of the seasonal and longitudinal variations of the NEPD was performed in two steps. First, the change of the NEPD throughout the 6 year period was derived, and then the seasonal variation was derived through averaging the values in the pixels that had the same day of the year (DOY hereafter). Finally, the NEPD values that were averaged in each pixel were smoothed with the directly neighboring pixels and a contour was generated.

Figure 4 presents the longitudinal variation of the NEPD for the period from 2005 to the end of 2010, while Figure 5 presents the seasonal variation as a function of the day of the year. As seen in Figure 4, seamless observations of the electron density profiles were obtained consistently, except for approximately 4 weeks in early October 2005 when the scientific payload was off. There are some missing observations from time to time, but they are not clearly seen in the contour map; however, they will be more clearly illustrated in the following figures in this paper.

Although the longitudinal variation of the NEPD does not repeat precisely the same pattern, seasonal behaviors exist. The most prominent seasonal behavior is that the wave- 3 structures that are centered at $90^{\circ}, 180^{\circ}$, and $270^{\circ} \mathrm{E}$ are apparent in October every year. While the enhanced EIA in the vicinity of $90^{\circ} \mathrm{E}$ did not change its longitude throughout the study period even the intensity changes as a function of DOY, the other structures at $180^{\circ}$ and $270^{\circ} \mathrm{E}$ changed their positions to be combined at approximately $220^{\circ} \mathrm{E}$ around December and then separated back to their original positions until the end of March every year. The enhancements in the NEPD near $0^{\circ} \mathrm{E}\left(30^{\circ} \mathrm{W}-30^{\circ} \mathrm{E}\right)$ only appeared in the Northern Hemisphere winter, but they were weak when compared with other structures. Arbitrary variations that cannot be only attributed to the seasonal variation also existed.

Through combining all data that were used to generate the map in Figure 4, a seasonal variation map as a function of the DOY was generated as seen in Figure 5. In this map, the abovementioned seasonal behavior of wave structures appeared more clearly. Furthermore, the NEPD exhibited a clear decrease under 1.5 in the Northern Hemisphere summer (June to July). There exists long-term variation in the NEPD as appeared in Figure 4. A slight increase from 2005 to 2006 is considered to be influenced by the altitude change from $710 \mathrm{~km}$ in 2005 to $660 \mathrm{~km}$ afterward. The NEPD distribution shows clear decrease in 2010 which is considered to be related with solar cycle effect. The long-term variation was found by applying a scale factor for the 6 year average (Figure 5) to minimize the least squares deviation from the annual average (Figure 4). The long-term variation found in this way was used as a reference from which the deviation of the NEPD was examined in order to obtain relations to the seismic activities. 


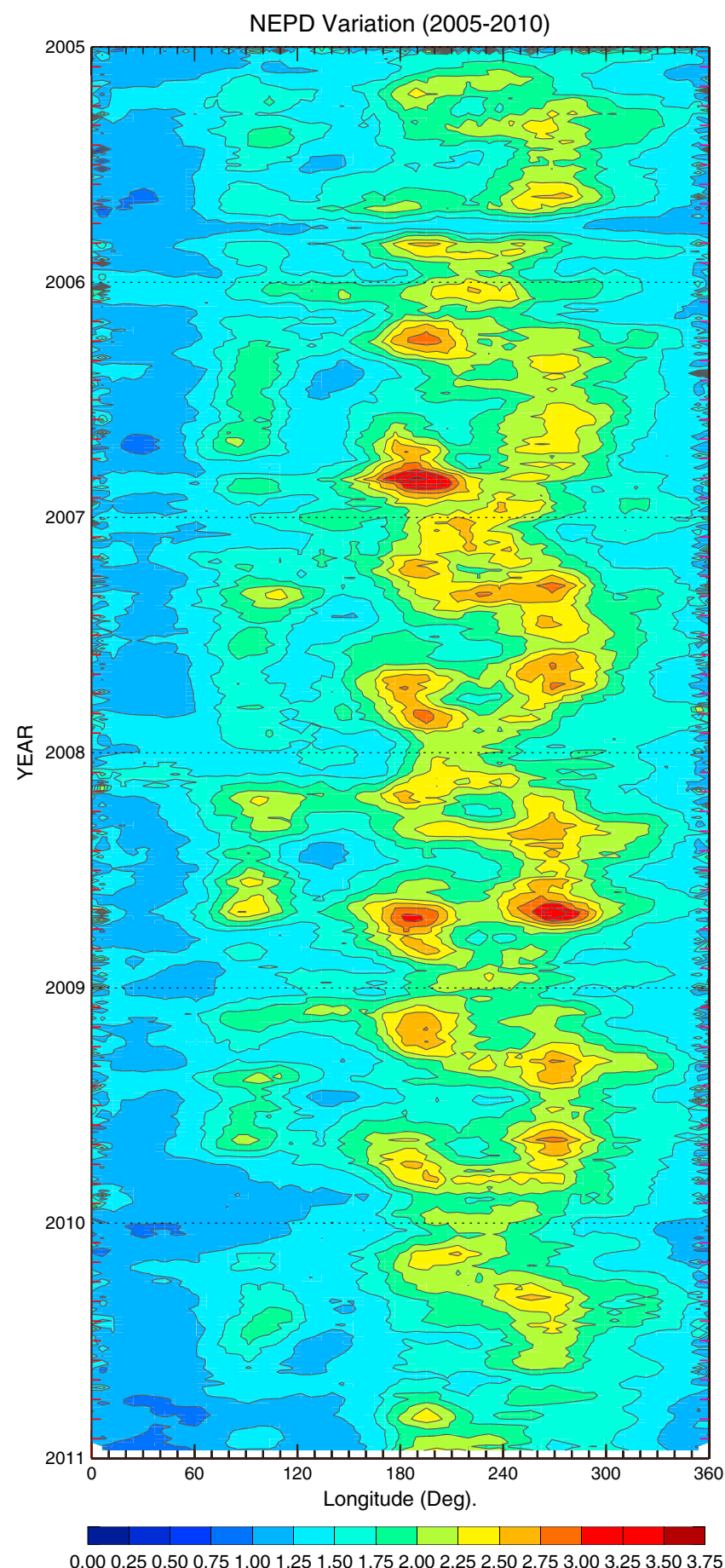

Figure 4. The contour map of the temporal and spatial variation of the NEPD during the study period (2005-2010). The horizontal axis represents the geographic longitude, while the vertical axis is the time in years. The method of generating the contour map is described in the text.

\subsection{Earthquake Occurrence and EIA Enhancement}

The longitudinal-seasonal contour map of the NEPD derived in the previous subsection is useful for understanding the overall behavior of the equatorial ionosphere related to the fountain effect, and it can be used as a reference. If seismo-ionospheric couplings exist in the form of equatorial anomalies, it should appear as additional deviations from the reference.

Because the earthquake positions are distributed in a two-dimensional space, it is not easy to link and compare with the references. Even if the geomagnetic latitude range of the epicenters is constrained in order to reduce the problem to a one-dimensional space, it remains complicated because all longitudes should be considered as a function of time.

In order to simplify the analysis, we restricted the study area to the three frequent earthquake regions, as defined in Figure 3. In order to separate Regions $A$ and $B$, the longitudinal ranges were defined as $\pm 12.5^{\circ}$ from the center longitude. Region A was defined as $92^{\circ} \pm 12.5^{\circ} \mathrm{E}$, while Regions $B$ and $C$ were defined as $125^{\circ} \pm 12.5^{\circ} \mathrm{E}$ and $290^{\circ} \pm 12.5^{\circ} \mathrm{E}$, respectively.

In order to determine whether a clear correlation appeared between the variation in the NEPD and the seismic activity, the NEPD changes and earthquake magnitudes in the three regions are presented as functions of time in Figures 6 to 11. The space weather conditions (Kp, Dst, and $\left.F_{10.7}\right)$, obtained from the OMNI data (for details, refer to http://omniweb.gsfc.nasa.gov), are also presented below each figure.

As noted above, numerous earthquakes occurred with varying magnitudes in the three regions. There is a tendency that the earthquakes were clustered in time.

For example, many earthquakes occurred in Region A (Figure 3b) during the first half of 2005, after which the occurrence rate was relatively low until the middle of 2007. The correlation between the earthquakes and NEPD is not seen clearly at first. Because the strength of the EIA represented by the NEPD varies when large earthquakes, severe geomagnetic storms, or solar activities occur, it would be dangerous to infer that the EIA and seismic activities are related through only surveying the graphs. 


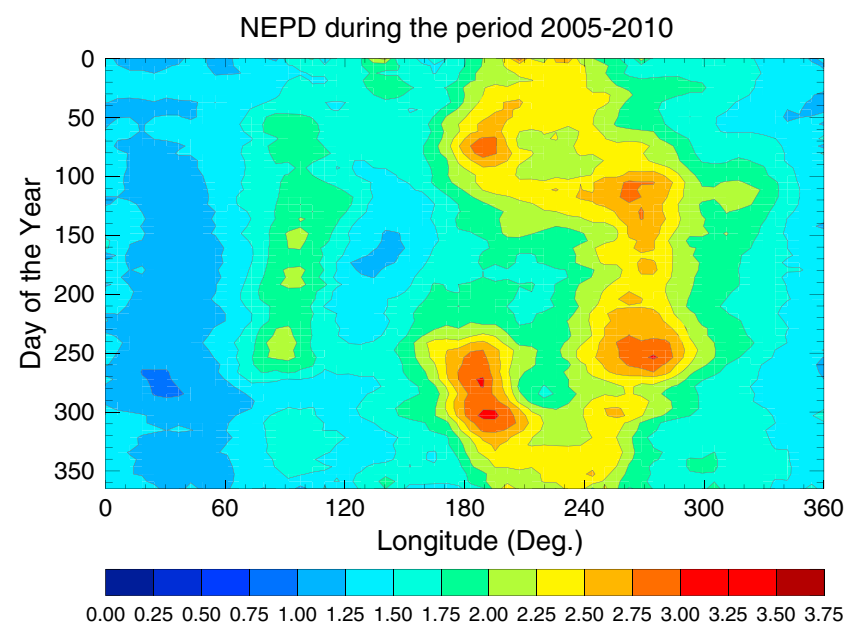

Figure 5. The seasonal and longitudinal variation of the NEPD during the study period. The vertical axis represents DOY. The data used in Figure 4 were averaged for the same DOY.
We attempted to identify the cases when the NEPD increases were related to the increased seismic activities, and these periods are marked using blue boxes in the figures. In 2005, there were three cases when the increases in both the NEPD and seismic activity coincided in the temporal and spatial viewpoints (Figure 6). Among these cases, the coherent increases of the NEPD, i.e., clearly larger than the $1 \sigma$ range of statistical reference, and the seismic activity were remarkable in the case of the northern Sumatra earthquake that occurred on 28 March 2005. The detailed temporal and longitudinal behaviors of the intensified EIA related to the earthquake were described by Ryu et al. [2014]. It appears that the ionosphere in Region B was also

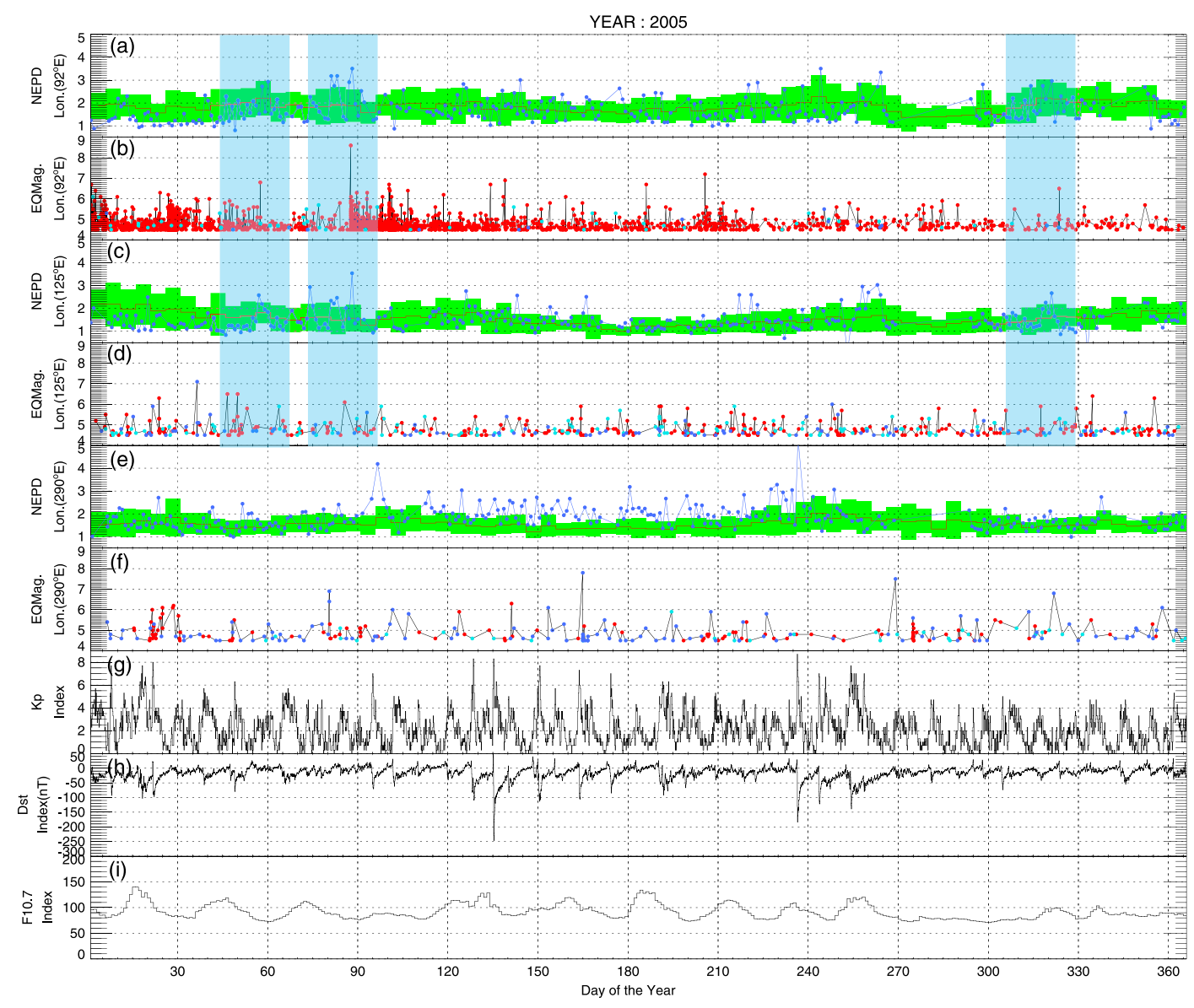

Figure 6. Variations of the NEPD, earthquake occurrence, and space weather conditions as functions of the DOY in 2005: (a) NEPD variation in Region A, (b) earthquake magnitude in Region A, (c) NEPD variation in Region $B$, (d) earthquake magnitude in Region B, (e) NEPD variation in Region C, (f) earthquake magnitude in Region C, (g) Kp index, (h) Dst index, and (i) $F_{10.7}$. The colors of the earthquakes represent the depth of the hypocenter. Red: depth < $50 \mathrm{~km}$; cyan: $50 \mathrm{~km}<$ depth $<100 \mathrm{~km}$; blue: depth $>100 \mathrm{~km}$. The cases suspected to be seismo-ionospheric coupling are marked as transparent blue boxes. The red lines and green bands in the NEPD plots represent the seasonal-longitudinal average and $1 \sigma$ range, which were derived from the measurements during the 6 year study period. 


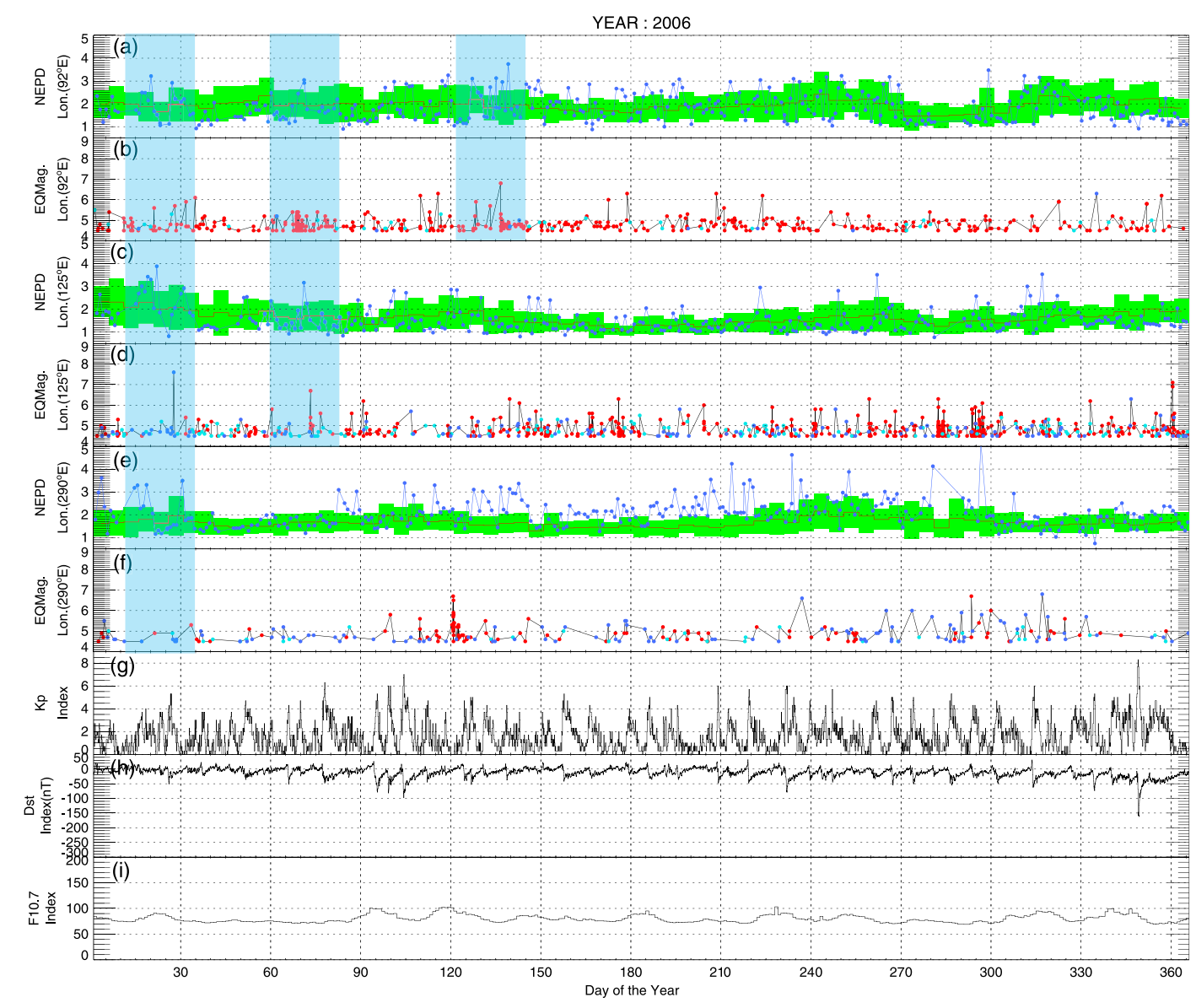

Figure 7. The same as Figure 6 for 2006.

affected by the seismic activity in the northern Sumatra earthquake, which was located in Region $A$. The other cases in 2005 exhibited similar behaviors.

In 2006, there were also three cases that were coincident in the NEPD increases and large earthquake occurrences (Figure 7). The Banda Sea earthquake of 27 January 2006 with a magnitude of 7.6 was the largest earthquake that occurred in the geomagnetic equator region $\left(15^{\circ}<\right.$ geomagnetic latitude $\left.<15^{\circ}\right)$ in 2006. The NEPD was increased globally 2 weeks prior to and 1 week after the main shock. There was a peak-like increase in the $K p$ index over 4.0, but this did not coincide with the increases of the NEPD. Considering that the typical feature of seismic effects in the ionosphere is its local characteristic, it is questionable that the NEPD increase was caused by the seismic activity.

Around the 80th day of 2006, a series of earthquakes occurred in Region A although their magnitudes were not large (less than 5.0). Increases in the NEPD in Regions A and B were observed immediately after the earthquakes, but the M6.7 Seram Indonesia earthquake of 14 March 2006 also occurred in Region B $\left(3.593^{\circ} \mathrm{S}, 127.211^{\circ} \mathrm{E}\right)$. If the NEPD increases in Regions A and B were triggered by the Seram Indonesia earthquake (2006), then they could be regarded as precursory phenomena. Region B was seismically active from the end of 2006 to the first quarter of 2007. The M7.5 Molucca Sea earthquake of 21 January 2007 was the largest earthquake in this period, as seen in Figure 8d. The NEPD in Regions A and B exhibited clear increases from early January 2007. The NEPD in Region B, where the Molucca Sea earthquake occurred, exhibited a tendency of the enhanced EIA diminishing as the earthquake time approached, and it returned within the $1 \sigma$ range afterward.

Another example that demonstrates the temporal and spatial correlation between the ElA strength and seismic activity in 2007 is the M8.0 Pisco earthquake that occurred on 15 August 2007 (Figures 8e and 8f). The NEPD increased above $3 \sigma$ approximately 1 week before and was maintained until a few days after the 


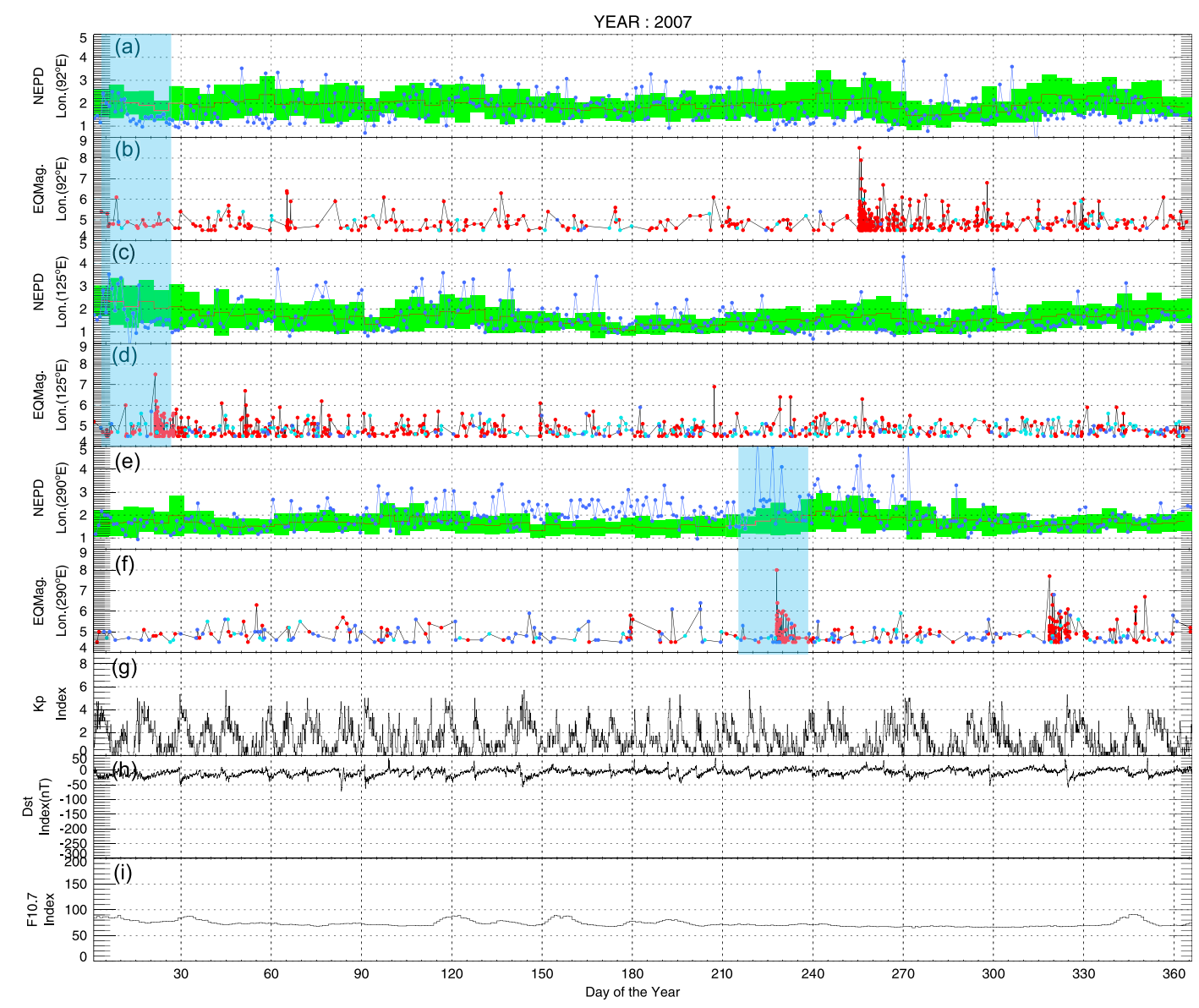

Figure 8. The same as Figure 6 for 2007.

earthquake; then, it returned to normal values. In 2008, the M7.4 Simeulue Indonesia earthquake of 20 February in Region A was the largest earthquake in the study areas (Figure 9b). The NEPD exhibited severe fluctuations around the earthquake occurrence, but the NEPD in Region A exhibited a large fluctuation afterward throughout the remainder of the year. This implies that the large increases of the NEPD are not always collocated with the seismic activities.

Meanwhile, the NEPD values in Regions A and B from the middle of April to early May in 2008 showed coincident increases without any apparently large earthquakes in the equator region (transparent red boxes in Figure 9). In Region A, the NEPD increased up to 4.8, the maximum in the year, at 125th day. It was 8 days before the occurrence of M7.9 eastern Sichuan, China earthquake (also known as Wenchuan earthquake) of 12 May (133th day) $2008\left(30.986^{\circ} \mathrm{N}, 103.364^{\circ} \mathrm{E}\right.$, depth $\left.=19 \mathrm{~km}\right)$ whose epicenter longitude belongs to Region A. This suggests that large earthquakes in the midlatitude can also affect the equatorial ionosphere. Many studies have already described the precursory increase of the TEC related to this earthquake [Zhao et al., 2008; Pulinets et al., 2010; Klimenko et al., 2011]. In addition, Zhang et al. [2010] studied the $N_{e}$ data recorded by DEMETER around this earthquake and found the similar variation with those from TEC on 9 May 3 days before the event.

In the first half of 2009 , the M7.2 Kepulauan Talaud Indonesia earthquake of 11 February $\left(3.902^{\circ} \mathrm{N}\right.$, $126.400^{\circ} \mathrm{E}$ ) was the largest earthquake in the study area (Figure 10d). For this earthquake, the NEPD exhibited increases in the three regions approximately 2 weeks before the main shock. These variations were not related to changes in the space weather indices $\left(K p, D s t\right.$, and $\left.F_{10.7}\right)$. However, the fluctuation in Region $B$, where the earthquake occurred, was larger than those of the other regions, which implies that the increments in the EIA strength were related to the earthquake.

Three cases of possible seismo-ionospheric coupling in 2010 are illustrated in Figure 11. It is interesting that the first two cases appear to be related to large earthquakes in Region A, and fluctuations in the NEPD were 


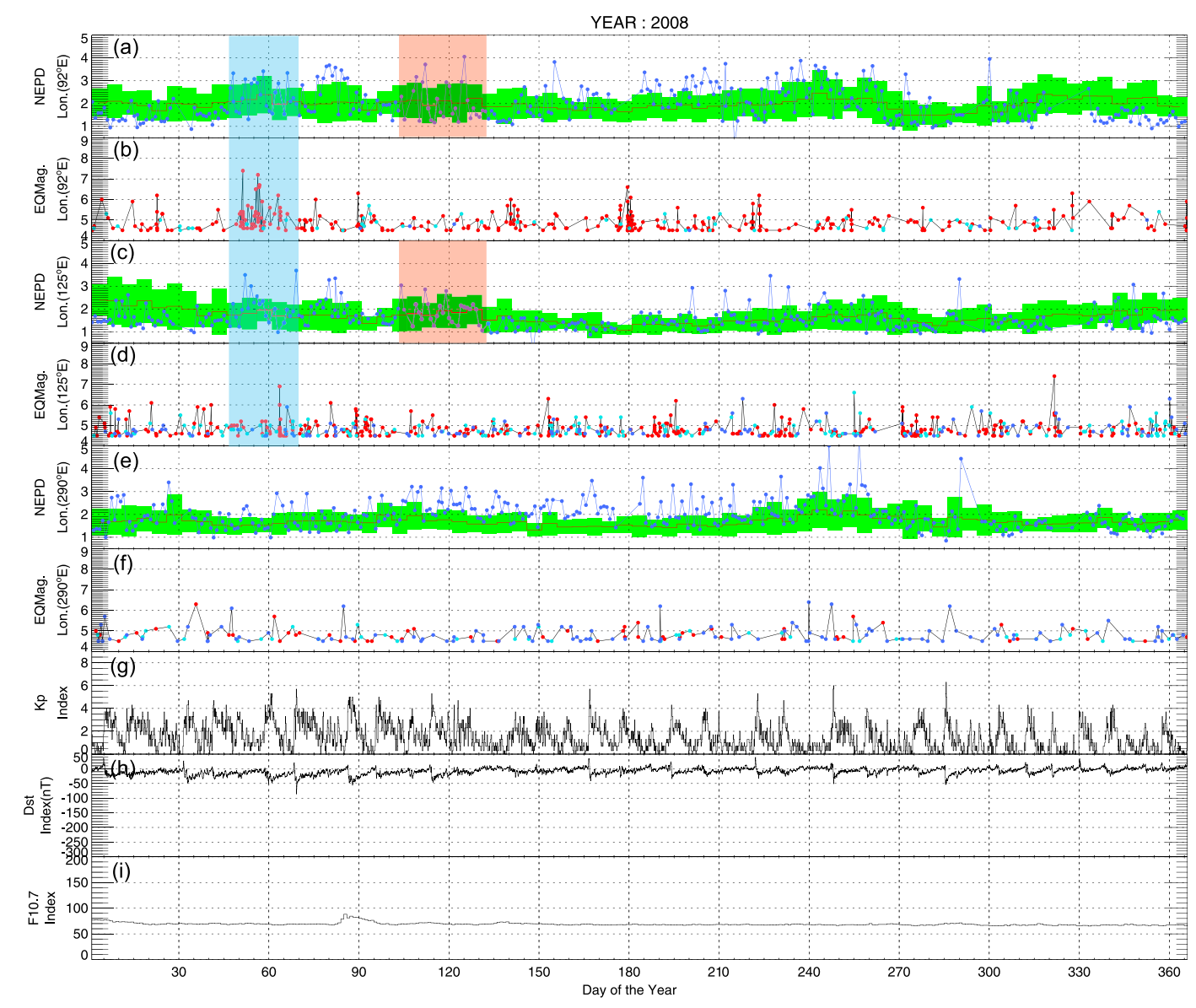

Figure 9. The same as Figure 6 for 2008.

found also in Region B. For the M7.8 northern Sumatra earthquake of 6 April 2010 (the second example in Figure 11), the NEPD exhibited a steep increment on the day of the earthquake occurrence with a coincident increment in the $K p$ index. However, because the NEPD did not exhibit apparent changes in Region $\mathrm{C}$ on the same day, this indicates that the example could be also a seismo-ionospheric coupling.

\subsection{Time Series Analysis and Results}

The examples of the seismo-ionospheric coupling, in the context of the NEPD changes or EIA enhancements, were investigated through visual inspections of the 6 year long electron density data measured by the polar-orbiting Sun-synchronous satellite DEMETER. A number of examples demonstrated that the NEPD increased several days before and after the earthquake occurrences in the three frequent earthquake regions. Because the process of selecting the seismo-ionospheric coupling, which depends only on visual inspections, can be subjective and/or biased, the interpretation could vary from person to person. In order to quantify the possible seismo-ionospheric coupling, the method of time series analysis was used. First, we defined a time series of seismic activity as a daily sum of the earthquake activity indices starting from the first day of 2005 continuing until the last day of 2010.

The relationship between the magnitude of an earthquake $\left(M_{s}\right.$, Richter magnitude) and the total radiated seismic energy $\left(E_{s}\right.$,joules) was established by Gutenberg and Richter [1956] as $\log E_{s}=1.5 M_{s}+4.8$. Although it can be estimated that the intensity of the seismo-ionospheric coupling should be proportional to the seismic energy, large earthquakes with magnitudes larger than 8.0 would be too dominant so that other earthquakes cannot contribute to the statistics at all. Therefore, instead of directly using the seismic energy, we defined the seismic activity index as an exponential of the earthquake magnitude. The reason for using an exponential function can be found in the strain field models of Dobrovolsky et al. [1979] and Fleischer [1981]. They gave a relation between earthquake magnitude and the radius of the effective precursory manifestation zone, where radon anomaly occurs, as $D=10^{0.43 M}$ (note that $10^{0.43}$ is $\sim 2.69$, while Euler's 


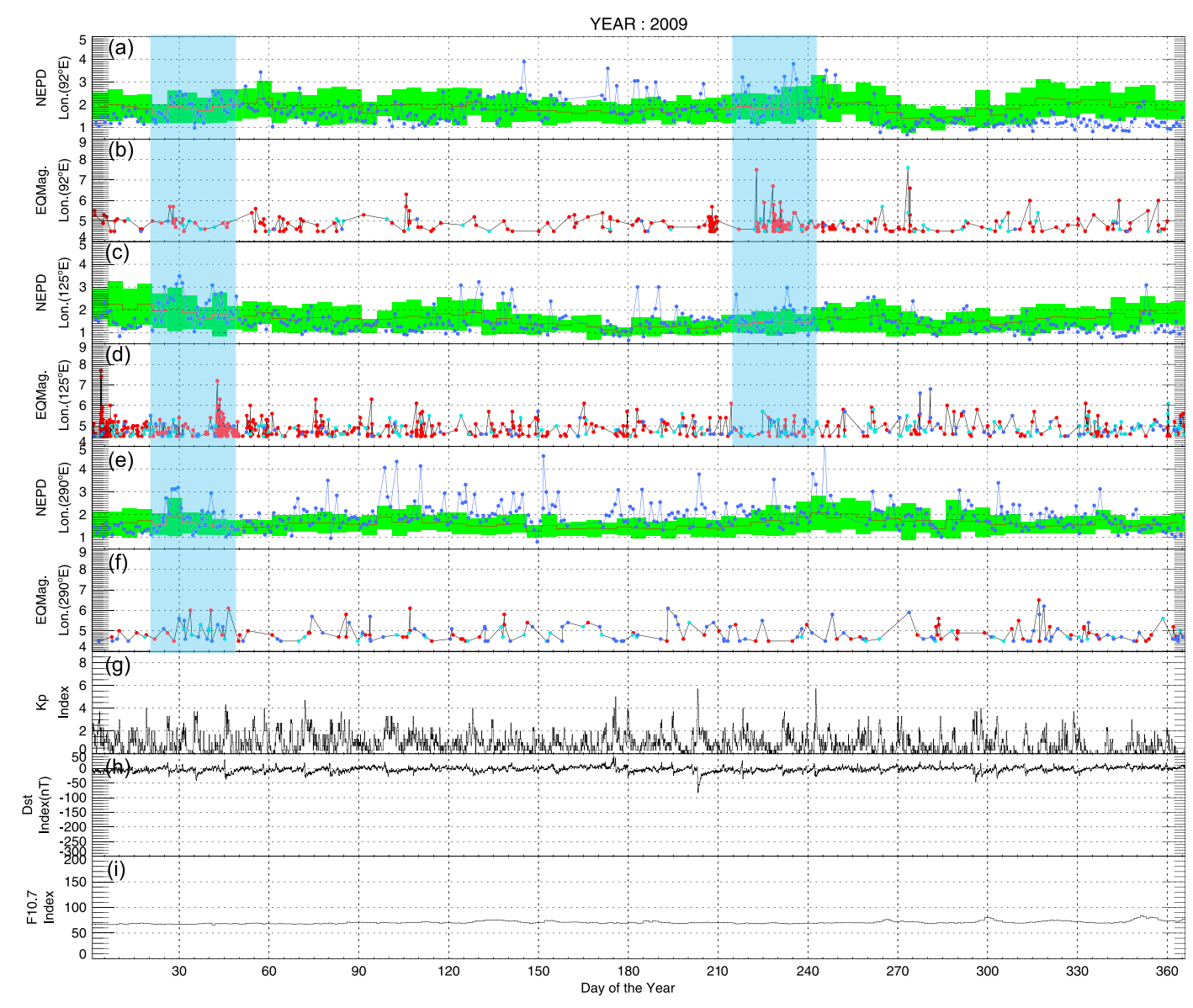

Figure 10. The same as Figure 6 for 2009.

number $e$ is $\sim 2.72$ ), where $D$ is the epicentral distance in $\mathrm{km}$, which is thought to be proportional to the intensity of the seismic signal in the ionosphere, and $M$ is the magnitude of the earthquake on the Richter scale. Beside the theoretical and empirical relation study, Walia et al. [2005] performed soil-gas and groundwater radon monitoring in N-W Himalayas and revealed that there exists significant correlation between the precursory radon anomalies and microseismic events in the vicinity. Thus, the time series of the seismic activity at the $i$ th day $\left(x_{j}\right)$ was defined as the sum of the individual seismic indices, as follows: $x_{\mathrm{R}, i}=\sum_{j} \exp \left(M_{\mathrm{R}, i j}\right)$, where $M_{\mathrm{R}, i j}$ represents the magnitude of the $j$ th earthquake in Region $\mathrm{R}(\mathrm{A}, \mathrm{B}$, or $\mathrm{C})$ at the $i$ th day from the first day of 2005. Using the sum of magnitude instead of the exponential yield essentially the same results, but using the exponential of the magnitude amplifies the statistics enough to show the possible correlations.

For the NEPD, the process of defining the time series was more complicated than that of the seismic index, because the EIA intensity is a function of the season, region, solar activity, geomagnetic activity, and so on. The study period was relatively calm in solar activity, so the effect of the $F_{10.7}$ index variation was not considered. In order to exclude the effect of the geomagnetic activity, the NEPD values from the day before to the day after the occurrence with $K p>3.0$ were substituted with the seasonal-regional average for each region derived from the 6 year average, which was introduced in Figure 5. The EIA strength index used in the analysis was detrended through taking the deviation $(\triangle N E P D)$ between the seasonal-regional average and the maximum value in the day. In order to reflect the observational tendency that some large earthquakes have a significant increase in the NEPD, we emphasized the EIA enhancement through using the exponential of the $\triangle$ NEPD that was analogous to the case of seismic activity index. That is, the time series of the EIA index at the ith day in Region $\mathrm{R}\left(y_{\mathrm{R}, i}\right)$ was defined as follows: $y_{\mathrm{R}, i}=\exp \left(\Delta \mathrm{NEPD} \mathrm{R}_{\mathrm{R}, i}\right)$. The results are essentially the same except the amplification of the correlation compared with using the $\triangle$ NEPD itself. 


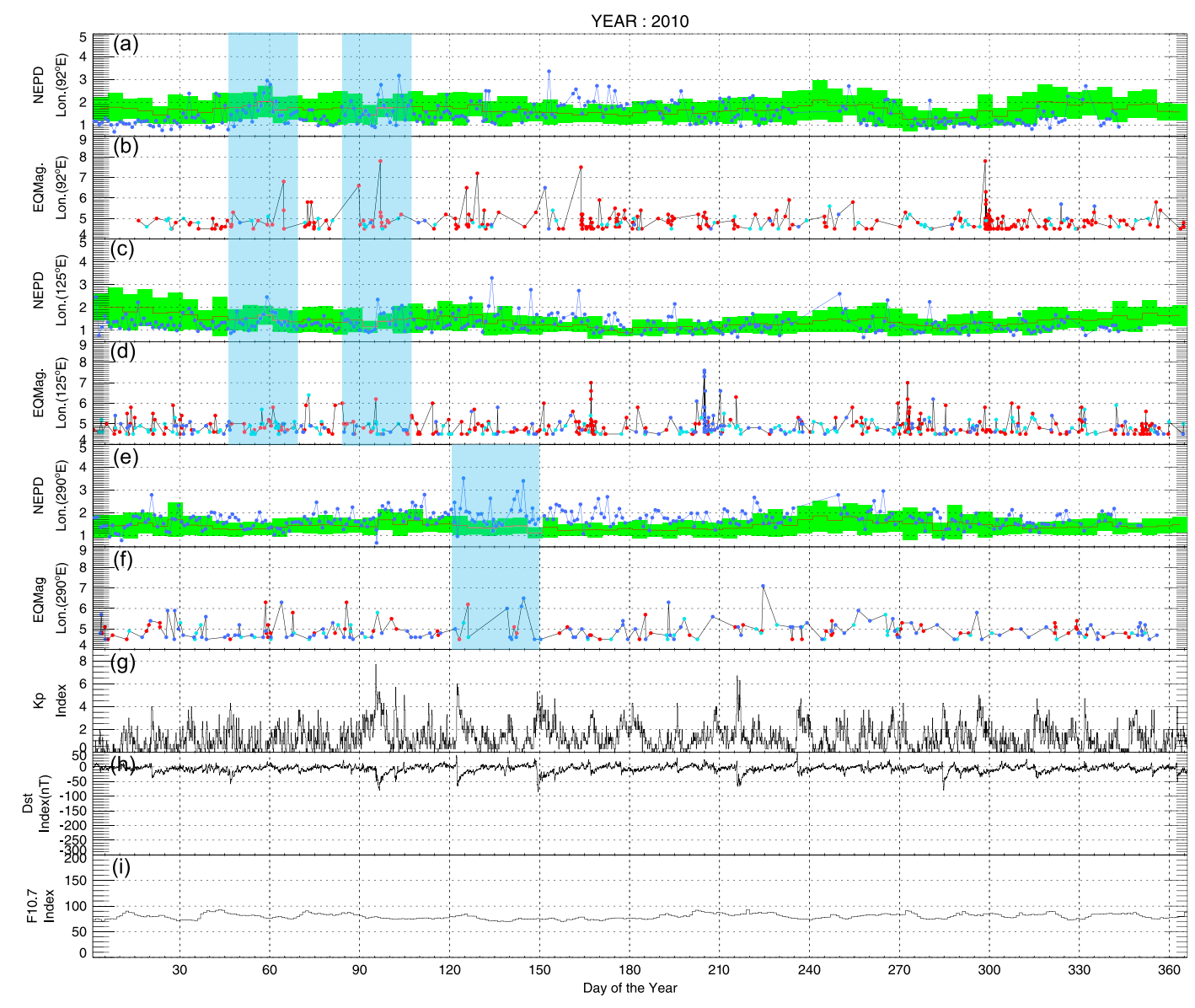

Figure 11. The same as Figure 6 for 2010.

The time series data of the earthquake index and EIA index, defined as described above according to the frequent earthquake regions, are presented in Figure 12. The first 30 days of earthquake index in Region $A$ was omitted because of the exceptionally large values, which can lead to edge effect in statistical analysis. The correlation between the two indices is not clearly observable at a glance, but some large earthquake indices accompanied abrupt increases in the EIA index. This feature was more apparent in Region B (Figure 12b).

In order to determine whether the NEPD variation preceded the seismic activity or vice versa, the lagged cross-correlation functions (hereafter, LCCF) [Chatfield, 2004] were estimated from the time series analysis. If $k$ denotes the lag, the $\operatorname{LCCF}\left(P_{x y}(k)\right)$ is defined as follows:

$$
P_{x y}(k)=\left\{\begin{array}{l}
\frac{\sum_{i=1-k}^{N}\left(x_{i}-\bar{x}\right)\left(y_{i+k}-\bar{y}\right)}{\sqrt{\left[\sum_{i=1}^{N}\left(x_{i}-\bar{x}\right)^{2}\right]\left[\sum_{i=1}^{N}\left(y_{i}-\bar{y}\right)^{2}\right]}} \text { for } k<0, \\
\frac{\sum_{i=1}^{N-k}\left(x_{i}-\bar{x}\right)\left(y_{i+k}-\bar{y}\right)}{\sqrt{\left[\sum_{i=1}^{N}\left(x_{i}-\bar{x}\right)^{2}\right]\left[\sum_{i=1}^{N}\left(y_{i}-\bar{y}\right)^{2}\right]}} \text { for } k \geq 0 .
\end{array}\right.
$$

Here $N$ denotes the number of samples corresponding to $N=365 \times 6=2,190$ in this study, while $\bar{x}$ and $\bar{y}$ represent the average values of the respective time series data. If the resultant LCCF has values larger than the significant level for negative $k$, then it implies that the EIA index preceded the earthquake index in time, and vice versa. The approximate $99 \%$ confidence level is given as $\pm 2.6 / \sqrt{N}$, where $N$ is the sample size.

Figure 13 presents the results of the time series analysis for the three regions. The autocorrelation functions of the earthquake index and the EIA index are presented together in order to determine whether erroneous results exist caused by repeated time series with a specific frequency. For example, small peaks in the autocorrelations of the earthquake index in Regions A and B (Figures 13a and 13b) prevent the misinterpretation of the LCCF at the corresponding lag $k$. While the LCCF of Region A does not exhibit statistically 
(a)

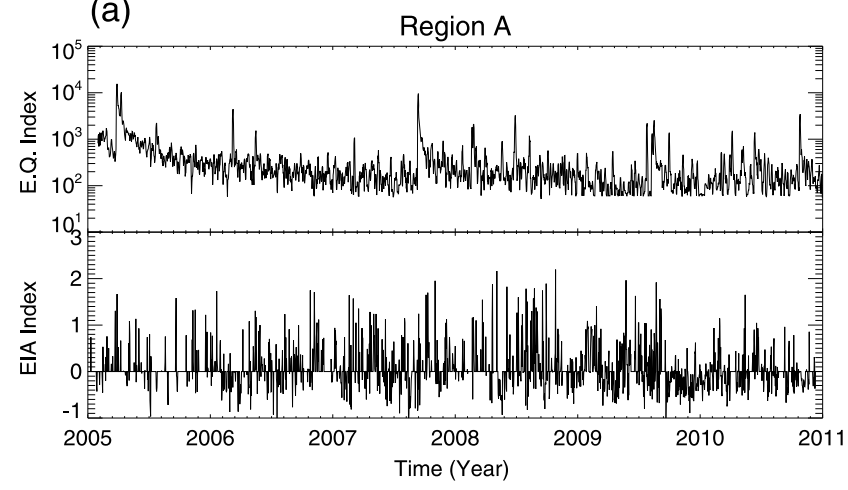

(b)

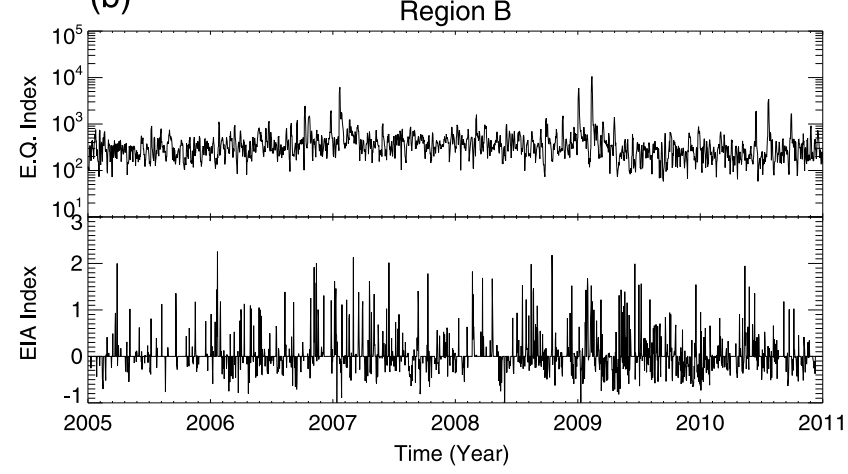

(c)

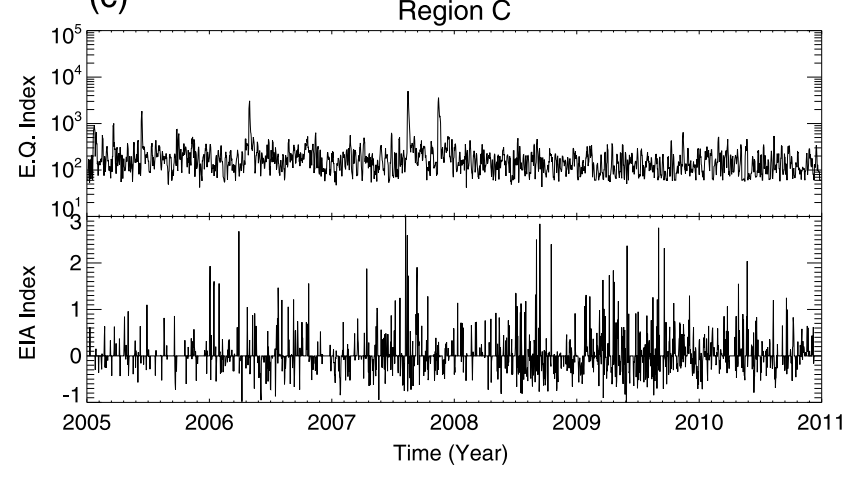

Figure 12. Time series of the earthquake index and EIA intensity index for (a) Region A, (b) Region B, and (c) Region C. The data were defined daily during the study period (2005-2010). significant results regardless of the lag $k$, Regions $B$ and $C$ had results larger than the $99 \%$ confidence level when $k<0$. Among the results, Region $B$ had a lagged cross correlation significantly larger than the confidence interval in the range of $-20<k<0$ reaching 0.25 at $k=-14$. It is noteworthy that Region $B$ is free from wave- 4 structures, while Regions $A$ and $C$ are bound to the tidal effect that influences the EIA strength variation. The statistical time series analyses in Regions B and $C$ implied that the EIA was enhanced from approximately 2 weeks before to a few days after the occurrence of very large earthquakes or the series of concentrated moderate-sized earthquakes. Although the enhanced NEPD was not always followed by large earthquakes and large earthquakes did not always accompany NEPD increases, some large earthquakes exhibited clear precursory increases sufficiently large to affect the statistical analysis. In addition, the increases of the EIA intensity caused by the seismo-ionospheric coupling dominant over the other effects, such as neutral wind, geomagnetic activity, solar activity, solar wind, etc., appeared to be limited to some of the very strong earthquakes, e.g., $M_{s}>5.0$.

\section{Discussion}

\subsection{Sensitivity to Other Parameters} It is well known that the solar activity and the geomagnetic activity affect the ionospheric density and temperature [Kelley, 1989] via the photoionization, plasma-wave interaction, and plasma

flow driven by the electromagnetic interactions. To investigate how the NEPD index is sensitive to the space weather indices, the LCCF of the EIA index ( $\triangle \mathrm{NEPD}$ ) with respect to the $K p, D s t$, and $F_{10.7}$ indices were derived as shown in Figure 14 with the autocorrelations of each indices. For the sake of simplicity, only the results for the Region A were shown because the results for the other regions are similar.

The indices commonly show the solar rotation effects of 27 day period with apparent peaks in case of Dst. Meanwhile, the LCCF does not show significant values commonly in three cases (Figures 14a-14c) except slight anticorrelation in case of $K p$. In case of the LCCF between $F_{10.7}$ and the EIA index (Figure 14c), it has quite lower value. This biased LCCF is attributed to the asymmetric distribution of the $F_{10.7}$ indices with respect to its average. In other words, the value is lower than its average most of the time and this could make such a bias in the LCCF output. There are low correlations with the indices because both the equatorial and midlatitude electron densities increase or decrease together as the space weather condition changes. The anticorrelation in case of $K p$ is explained by the increase of the midlatitude electron density when the geomagnetic activity increased and the polar ionosphere expanded to the geomagnetic latitude less than $50^{\circ}$. The LCCF between $\mathrm{Kp}$ index and the midlatitude electron density (Figure 14d) supports 

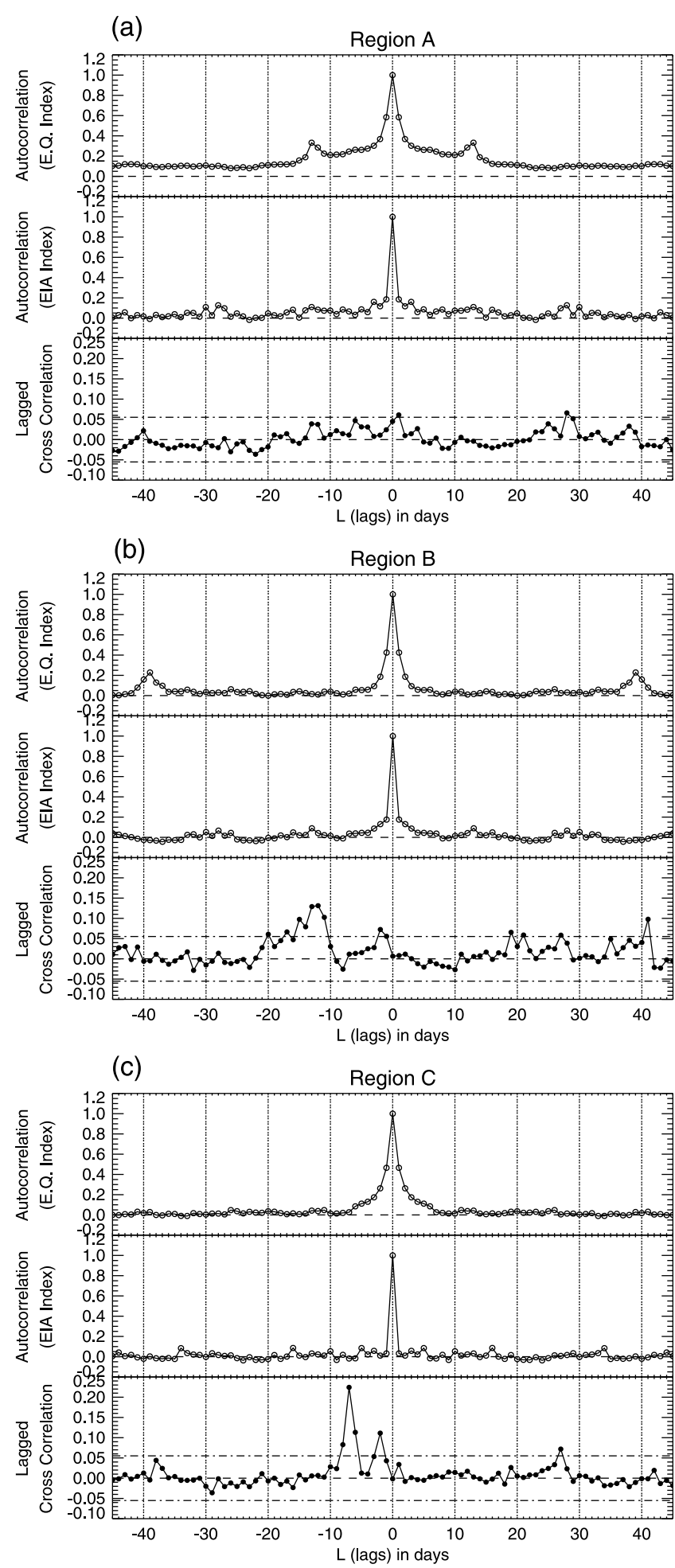

Figure 13. The lagged cross-correlation functions for (a) Region $A$, (b) Region $B$, and (c) Region C. The autocorrelation functions of the earthquake index and the EIA intensity index are presented together in order to determine whether an erroneous interpretation caused by periodic values in the earthquake index or EIA intensity index exists. The dashed lines in the lagged cross-correlation function represent $99 \%$ confidence intervals. that the slight anticorrelation between $K p$ and EIA index was caused by the increase of the midlatitude electron density.

As described previously, the three studied regions were selected because of frequent earthquakes which made the statistical analysis possible and reliable as well. If the EIA index variation in a region with few earthquakes can have significant LCCF with a random earthquake series or earthquake index defined for other regions (Regions A, B, and C), then the LCCF values larger than the significant interval introduced in the previous section can be regarded as a coincidence. To investigate the possibility, additional study region in $45 \pm 12.5^{\circ} \mathrm{E}$ with fewer earthquakes located off the wave structure was defined based on the earthquake distribution map (Figure 3).

The same methodology was applied, and the results are shown in Figure 15. As shown in Figure 15c, the LCCF does not have values that exceed the significant interval. It is thought that the fewer earthquakes with smaller magnitudes could have yield small LCCF values in the region. Instead of applying artificially generated random earthquake series, the earthquake indices already defined for Regions A, B, and C were used and the results are shown in Figure 15d. As appeared in the graph, the LCCF between the EIA index in the sample region and the earthquake indices for the three study areas did not exceed the significant interval throughout the defined lags ( -45 to 45 days). This implies the LCCF values that exceed the significant interval obtained for the three-study regions with frequent earthquakes cannot be regarded merely as a coincidence.

\subsection{Mechanism of the} Seismo-lonospheric Coupling and Possibility of the Earthquake Prediction The disturbances observed in the electron density measured by the DEMETER satellite provided opportunities to investigate the underlying process of seismo-ionospheric coupling, which is the probable driver of the intensified EIA. Unlike the low altitude satellites that had 


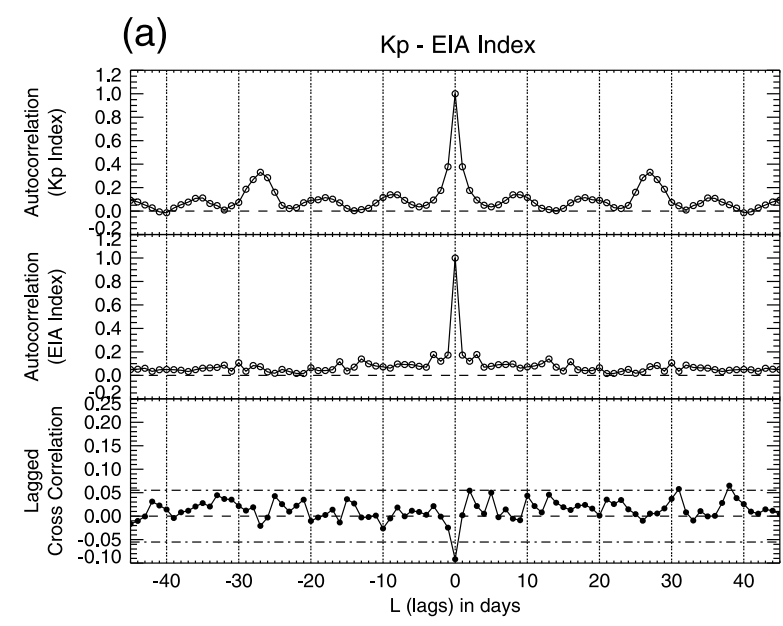

(c)

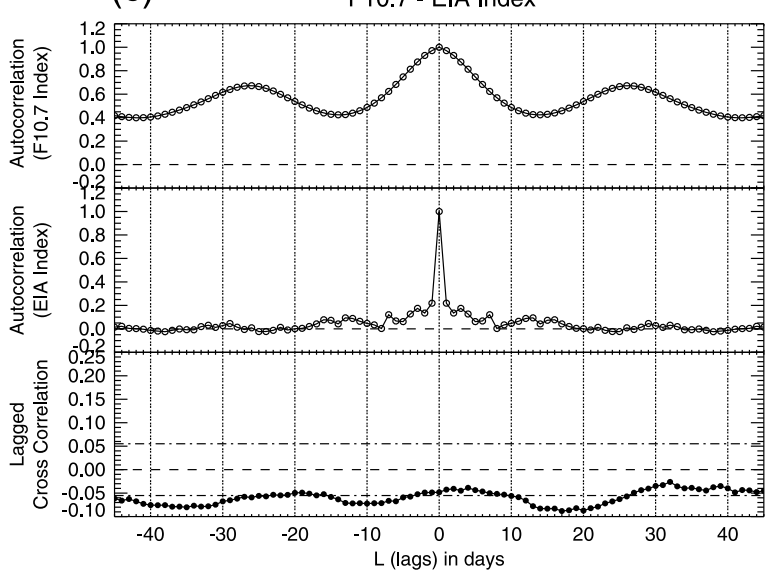

(b)

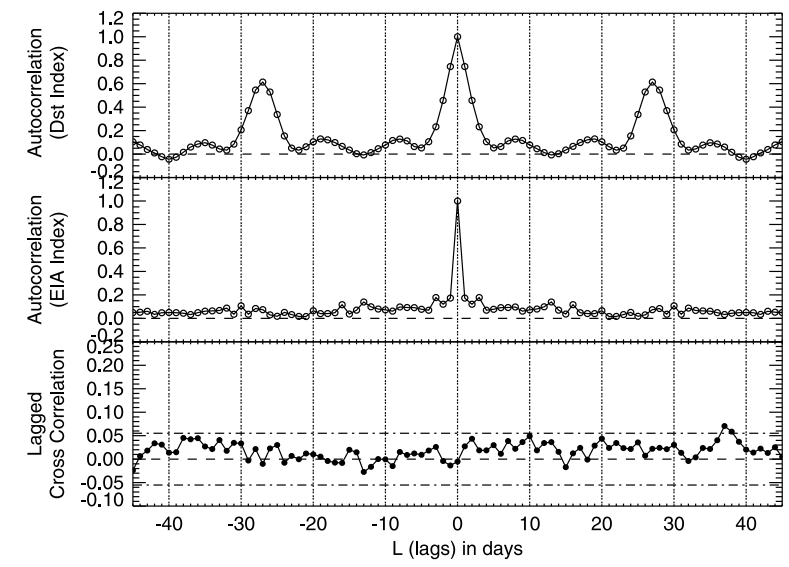

(d)

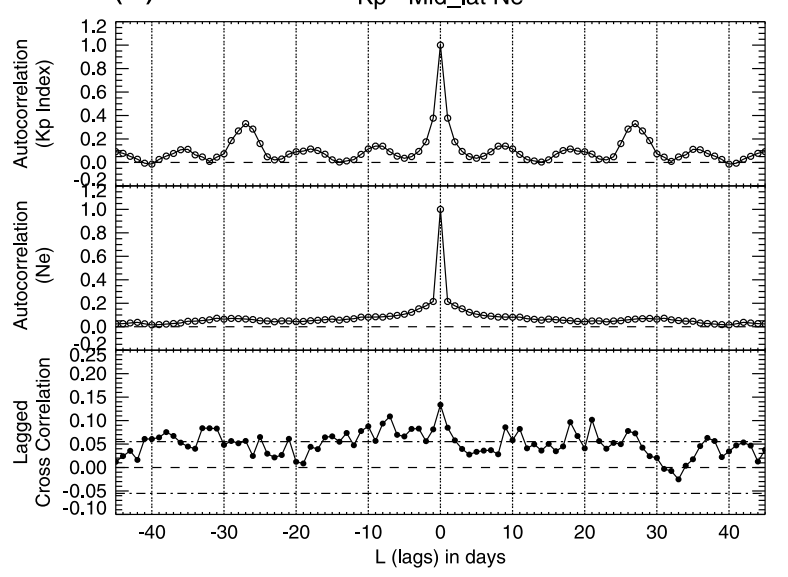

Figure 14. The lagged cross-correlation functions of EIA index ( $\triangle$ NEPD) with respect to (a) $K p$ index, (b) Dst index, and (c) $F_{10.7}$ index. The autocorrelation functions of each parameters are presented together. (d) Represent the lagged cross correlation of the midlatitude electron density with respect to $K p$ index.

small inclination angles, such as CHAMP, ROCSAT-1, and Communications/Navigation Outage Forecasting System, which were operated throughout the last decade, DEMETER provided a unique opportunity to survey the $F_{2}$ region ionosphere at a fixed local time (Sun-synchronous orbit) of 10:30 in the dayside, before the EIA strength is primarily derived by the daily dusk to dawn or eastward electric field.

The statistical study using the time series analysis method, i.e., the lagged cross-correlation function, revealed that some historically large earthquakes accompanied abrupt increases of the EIA strength, which were represented by the equatorial plasma density with respect to the midlatitude density. The seismo-ionospheric coupling appeared to initiate approximately 2 weeks before the seismic energy was released in the form of an earthquake and it disappeared afterward.

Pulinets [2012] reported that the longitudinal variation of the critical frequency $\left(f_{o} F_{2}\right)$ obtained with the topside sounder IS-338 was distorted from the so-called WN4 longitudinal structure 2 days before the M7.3 New Guinea earthquake of 16 July 1980 . The distortion, i.e., the reduction of the $f_{o} F_{2}$ in the vicinity of the epicenter in this case, was maintained until the day of the earthquake and then it disappeared. They explained that the longitudinal variation of the plasma density could result from the increased or decreased air conductivity through radon emanation in the epicenter region and followed by the decreased or increased ionospheric potential in the bottom of the $F$ region ionosphere.

Freund [2010] proposed that the positive holes generated by the squeezed rocks in the seismic preparation zone could ionize the air molecules and increase the conductivity. Once the air conductivity is increased, the following processes to change the ionospheric potential are the same as the radon emanation model. It is noteworthy that all frequent earthquake regions in the geomagnetic equator region investigated in this paper are located in the ocean, as shown in Figure 3. Ondoh [2003] explained that radon gas would 


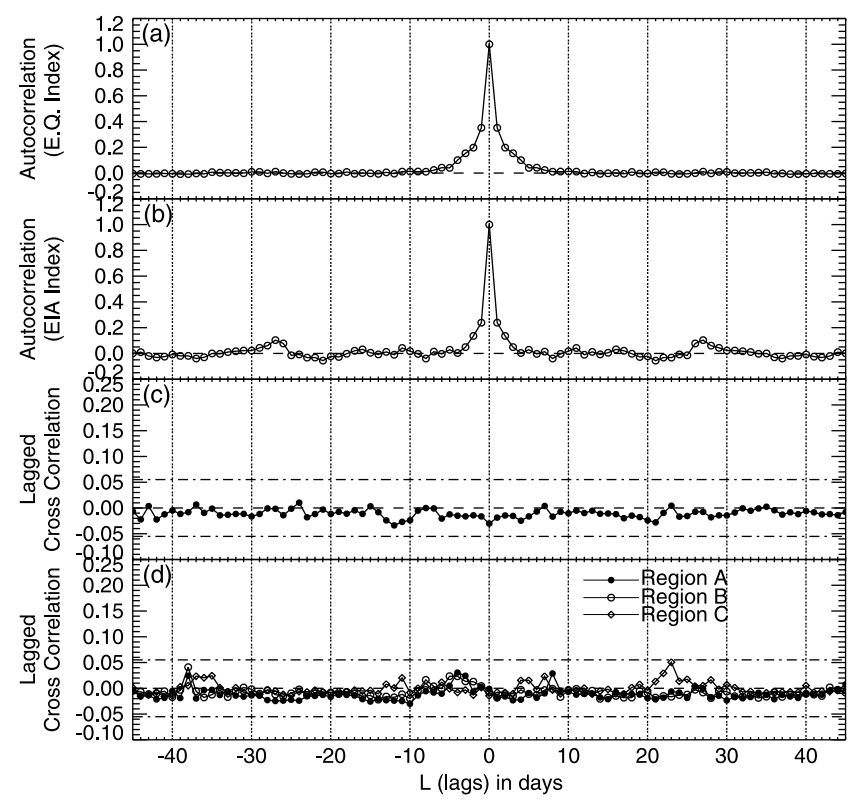

Figure 15. The autocorrelation functions of (a) the earthquake index and (b) the EIA index, and (c) the lagged cross correlation in the sample region with fewer earthquakes $\left(45^{\circ} \mathrm{E}\right)$. (d) The lagged cross correlation between the EIA index of the sample region with respect to the earthquake indices of other regions. emanate from the ground, including the land and sea surfaces [Pulinets, 2012], to significantly ionize the air and that the radioactive decay of radon atoms through high-energy alpha particle emissions could cause the formation of ion pairs, and thus increase the air conductivity. Rycroft et al. [2008] described the process of the modified air conductivity at the Earth's surface leading to the consequent changes in the ionospheric potential. Harrison et al. [2010, 2014] applied this mechanism to explain the seismo-ionospheric coupling. Recently, Pulinets and Ouzounov [2011] presented a lithosphere-atmosphere-ionosphere coupling (LAIC) model to explain the earthquake precursor phenomena.

Using numerical simulations, Kuo et al. [2011] demonstrated that the atmospheric ionization and the following increase of conductivity can jointly trigger an upward electric current over the seismo-active region and form a horizontal electric field at the bottom of the ionosphere that initiates the vertical or zonal drift of the ionospheric plasma according to the magnetic field direction. In the equatorial region, the magnetic field lines are almost parallel to the Earth's surface so that the zonal electric field takes effect and then the $\mathbf{E} \times \mathbf{B}$ initiates the vertical drift toward an upward or downward direction of the ionospheric potential configuration. At the DEMETER altitude, the plasma density decreased exponentially as the altitude increased. The changes in the NEPD could be attributed to this vertical movement. Because the density gradient is larger at lower altitudes in the DEMETER orbit, the upward movement would be more apparent regardless of the ionospheric potential configuration. Later, Kuo et al. [2014] improved their LAIC (lithosphere-atmosphere-ionosphere coupling) model to incorporate any arbitrary angle of magnetic field, i.e., any magnetic latitude. According to their results, the increase or decrease of $N_{e}$ occurs only in the limited regions around epicenter and its geomagnetic conjugate without change in the equatorial ionosphere because the magnetic field has steep angle with respect to the horizon in the midlatitude regions.

We attempted to eliminate the effects other than the seismo-ionospheric coupling through detrending the time series of the NEPD by subtracting the averaged seasonal-longitudinal variation. In addition, we excluded the effect of the geomagnetic activity through substitution with average values when $K p>3.0$. It was only possible to identify the seismo-ionospheric coupling for several historically large earthquakes and to demonstrate that precursory features exist. This implies that the seismo-ionospheric coupling was neither the main nor the only driver of the EIA variation. It is expected that the neutral wind or tidal wind would be the most probable candidate for the main driver because they are the drivers of WN4 structures [Immel et al., 2006], but they require significantly more improved instruments and resources for continuous observation of the neutral atmosphere or thermosphere. Then, it would be possible to understand the detailed process of the EIA variation and its relation to seismic activity. However, there is also reason to anticipate that the ionosphere can be monitored in similar conditions to those of DEMETER in the future and also to attempt earthquake prediction, even if it is limited to the equatorial region.

\section{Summary and Conclusions}

The variations of the EIA intensity in the geomagnetic equator region were investigated using the newly defined EIA index (NEPD) derived from the electron density measurements of the DEMETER satellite. Increases in the NEPD before some large earthquakes were identified and led to the statistical analyses of 
the possible seismo-ionospheric coupling. In order to reduce the complexity of the analysis, three regions with frequent earthquakes were selected and sets of time series of the seismic activity index and EIA intensity index were derived for each region during the 6 year period of DEMETER's stable observation (2005-2010). The effects of the space weather were eliminated and the seasonal-longitudinal variations of the EIA intensity were subtracted from the original time series. Then, the lagged cross-correlation functions between the seismic activity index and EIA intensity index were derived for unbiased statistical interpretation.

The results of the time series analysis indicate that the seismo-ionospheric coupling could be observed in the EIA intensity variation, at least for very large earthquakes $(M>5.0)$, and they accompany precursory enhancements. These features were observed for the earthquakes with the largest seismic energy in the three selected regions during the study period. The correlation was more clearly seen in the New Guinea and vicinity seismic zone where the tidal wind effect, i.e., the putative cause of wave-4 structures in the equatorial region, was minimized most among the three regions.

The physical models that could explain the presumable seismo-ionospheric coupling were investigated. Among these models, the conductivity increase due to the emanation of radon, which can ionize the atmosphere in the vicinity of the epicenter, the formation of a vertical current between the ground and the bottom of the ionosphere, and the following ionospheric potential change could explain the increased plasma density through an intensified $\mathbf{E} \times \mathbf{B}$ drift in the equatorial ionosphere. The potential for predicting large earthquakes in the equatorial region was discussed briefly. However, further rigorous observations and model studies are necessary for practical assessment of earthquake predictions using ionospheric disturbances.

\section{Acknowledgments}

This work was supported by grant CATER2012-5060 from the Center for Atmospheric Science and Earthquake Research (CATER) in Korea. The authors are grateful to the engineers and scientists who were involved in the development, operation, and data processes of the DEMETER satellite. We also thank H. Kil at Johns Hopkins University Applied Physics Laboratory, Y.-S. Kwak at Korea Astronomy and Space Science Institute, and Y.H. Kim at Chungnam National University for valuable comments on the behavior of the equatorial ionosphere. The DEMETER data used in this study were obtained via the CDPP data center (http://cdpp2.cnes.fr/cdpp), while the space weather data were obtained from the OMNI data center (http://omniweb.gsfc.nasa.gov). In addition, the earthquake data were acquired from the USGS-NEIC data center (http://earthquake.usgs.gov/regional/neic).

Alan Rodger thanks the reviewers for their assistance in evaluating the paper.

\section{References}

Anderson, D. N. (1981), Modeling the ambient, low latitude F-region ionosphere-A review, J. Atmos. Terr. Phys., 43, 753-762. Appleton, E. V. (1954), The anomalous equatorial belt in the F2-layer, J. Atmos. Terr. Phys., 5, 348-351.

Bankov, L., R. Heelis, M. Parrot, J.-J. Berthelier, P. Marinov, and A. Vassileva (2009), WN4 effect on longitudinal distribution of different ion species in the topside ionosphere at low latitudes by means of DEMETER, DMSP-F13 and DMSP-F15 data, Ann. Geophys., 27(7), 2893-2902, doi:10.5194/angeo-27-2893-2009.

Batista, I. S., E. M. Diago, J. R. Souza, M. A. Abdu, and G. J. Bailey (2011), Equatorial ionization anomaly: The role of themorspheric winds and the effects of the geomagnetic field secular variation, in Aeronomy of the Earth's Atmosphere and lonosphere, edited by M. A. Abdu, D. Pancheva, and A. Bhattacharyya, pp. 317-328, Springer Science+Business Media, Dordrecht, Netherlands.

Benkova, N. P., M. G. Deminov, A. T. Karpachev, N. A. Kochenova, Y. V. Kusnerevsky, V. V. Migulin, S. A. Pulinets, and M. D. Fligel (1990), Longitude features shown by topside sounder data and their importance in ionospheric mapping, Adv. Space Res., 10(8), 57-66.

Benz, H. M., M. Herman, A. C. Tarr, G. P. Hayes, K. P. Furlong, A. Villaseñor, R. L. Dart, and S. Rhea (2011), Seismicity of the Earth 1900-2010 New Guinea and vicinity: Open File Rep. 2010-1083-H, scale 1:8,000,000, U. S. Geological Survey, Denver, Colo. [Available at http://pubs. usgs.gov/of/2010/1083/h/.]

Berthelier, J. J., M. Godefroy, F. Leblanc, E. Seran, D. Peschard, P. Gilbert, and J. Artru (2006), IAP, the thermal plasma analyzer on DEMETER, Planet. Space Sci., 54(5), 487-501, doi:10.1016/j.pss.2005.10.017.

Chatfield, C. (2004), The Analysis of Time Series: An Introduction, 6th ed., 158 pp., Chapman and Hall/CRC, New York.

Coley, W. R., R. A. Heelis, M. D. Perdue, and R. A. Power, (2010), lonospheric monitoring and specification utilizing data from the defense meteorological satellite program, Sci. Rep., Univ. of Texas at Dallas, Richardson, Tex.

Cussac, T., M.-A. Clair, P. Ultré-Guerard, F. Buisson, G. Lassalle-Balier, M. Ledu, C. Elisabelar, X. Passot, and N. Rey (2006), The DEMETER microsatellite and ground segment, Planet. Space Sci., 54, 413-427, doi:10.1016/j.pss.2005.10.013.

Depuev, V. H., and S. A. Pulinets (2004), A global empirical model of the ionospheric topside electron density, Adv. Space Res., 34, 2016-2020, doi:10.1016/j.asr.2004.05.006.

Dobrovolsky, I., S. Zubkov, and V. Miachkin (1979), Estimation of the size of earthquake preparation zones, Pure Appl. Geophys., 117(5), 1025-1044, doi:10.1007/BF00876083.

England, S. L., S. Maus, T. J. Immel, and S. N. Mende (2006), Longitudinal variation of the E-region electric field caused by atmospheric tides, Geophys. Res. Lett., 33, L21105, doi:10.1029/2006GL027465.

Fleischer, R. L. (1981), Dislocation model for radon response to distant earthquakes, Geophys. Res. Lett., 8(5), 477-480, doi:10.1029/GL008i005p00477.

Freund, F. (2010), Toward a unified solid state theory for pre-earthquake signals, Acta Geophys., 58(5), 719-766, doi:10.2478/s11600-009-0066-X.

Gutenberg, B., and C. F. Richter (1956), Magnitude and energy of earthquakes, Ann. Geofis., 9, 1-15.

Harrison, R. G., K. L. Aplin, and M. J. Rycroft (2010), Atmospheric electricity coupling between earthquake regions and the ionosphere, J. Atmos. Sol. Terr. Phys., 72, 376-381, doi:10.1016/j.jastp.2009.12.004.

Harrison, R. G., K. L. Aplin, and M. J. Rycroft (2014), Brief communication: Earthquake-cloud coupling through the global atmospheric electric circuit, Nat. Hazards Earth Syst. Sci., 14, 773-777, doi:10.5194/nhess-14-773-2014.

Hayes, G. P., M. Bernardino, F. Dannemann, G. Smoczyk, R. Briggs, H. M. Benz, K. P. Furlong, and A. Villaseñor (2013), Seismicity of the Earth 1900-2012 Sumatra and vicinity: Open-File Rep. 2010-1083-L, scale 1:6,000,000, U.S. Geological Survey, Denver, Colo. [Available at http://pubs.usgs.gov/of/2010/1083/l/.]

Heelis, R. A. (2004), Electrodynamics in the low and middle latitude ionosphere: A tutorial, J. Atmos. Sol. Terr. Phys., 66, 825-838, doi:10.1016/j.jastp.2004.01.034. 
Immel, T. J., E. Sagawa, S. L. England, S. B. Henderson, M. E. Hagan, S. B. Mende, H. U. Frey, C. M. Swenson, and L. J. Paxton (2006), Control of equatorial ionospheric morphology by atmospheric tides, Geophys. Res. Lett., 33, L15108, doi:10.1029/2006GL026161.

Kakinami, Y., C. H. Lin, J. Y. Liu, M. Kamogawa, S. Watanabe, and M. Parrot (2011), Daytime longitudinal structures of electron density and temperature in the topside ionosphere observed by the Hinotori and DEMETER satellites, J. Geophys. Res., 116, A05316, doi:10.1029/2010JA015632.

Kakinami, Y., M. Kamogawa, T. Onishi, K. Mochizuki, J.-P. Lebreton, S. Watanabe, M.-Y. Yamamoto, and T. Mogi (2013), Validation of electron density and temperature observed by DEMETER, Adv. Space Res., 52, 1267-1273, doi:10.1016/j.asr.2013.07.003.

Kelley, M. C. (1989), The Earth's Ionosphere-Plasma Physics and Electrodynamics, 1st ed., 83 pp., Academic Press, New York.

Kil, H., E. R. Tallat, S.-J. Oh, L. J. Paxton, S. L. England, and S.-Y. Su (2008), Wave structure of the plasma density and vertical EXB drift in low-latitude F region, J. Geophys. Res., 113, A09312, doi:10.1029/2008JA013106.

Klimenko, M. V., V. V. Klimenko, I. E. Zakharenkova, S. A. Pulinets, B. Zhao, and M. N. Tsidilina (2011), Formation mechanism of great positive TEC disturbances prior to Wenchuan earthquake on May 12, 2008, Adv. Space Res., 48, 488-499, doi:10.1016/j.asr.2011.03.040.

Klimenko, M. V., V. V. Klimenko, I. E. Azkharenkova, and S. A. Pulinets (2012), Variations of equatorial electrojet as possible seismo-ionospheric precursor at the occurrence of TEC anomalies before strong earthquake, Adv. Space Res., 49, 509-517, doi:10.1016/j.asr.2011.10.017.

Kochenova, N. A. (1987), Longitudinal variations of the equatorial ionosphere according to Intercosmos-19 data, Geomagn. Aeron., 21(1), $142-144$.

Kuo, C. L., J. D. Huba, G. Joyce, and L. C. Lee (2011), lonosphere plasma bubbles and density variations induced by pre-earthquake rock currents and associated surface charges, J. Geophys. Res., 116, A10317, doi:10.1029/2011JA016628.

Kuo, C. L., L. C. Lee, and J. D. Huba (2014), An improved coupling model for the lithosphere-atmosphere-ionosphere system, J. Geophys. Res. Space Physics, 119, 3189-3205, doi:10.1002/2013JA019392.

Lagoutte, D., et al. (2006), The DEMETER science mission centre, Planet. Space Sci., 54(5), 428-440, doi:10.1016/j.pss.2005.10.014.

Lebreton, J.-P., et al. (2006), The ISL Langmuir probe experiment processing onboard DEMETER: Scientific objectives, description and first results, Planet. Space Sci., 54(5), 472-486, doi:10.1016/j.pss.2005.10.017.

Liu, H., C. Stolle, M. Förster, and S. Watanabe (2007), Solar activity dependence of the electron density in the equatorial anomaly regions observed by CHAMP, J. Geophys. Res., 112, A11311, doi:10.1029/2007JA012616.

Lühr, H., J. Park, P. Ritter, and H. Liu (2012), In-situ CHAMP observation of ionosphere-thermosphere coupling, Space Sci. Rev., 168, 237-260, doi:10.1007/s11214-011-9798-4.

Mendillo, M., B. Lin, and J. Aarons (2000), The application of GPS observations to equatorial aeronomy, Radio Sci., 35(3), 885-904, doi:10.1029/1999RS002208.

Mendillo, M., C.-L. Huang, X. Pi, H. Rishbeth, and R. Meier (2005), The global ionospheric asymmetry in total electron content, J. Atmos. Sol. Terr. Phys., 67, 1377-1387, doi:10.1016/j.jastp.2005.06.021.

Namgaladze, A. A., M. V. Klimenko, V. V. Klimenko, and I. E. Zakharenkova (2009), Physical mechanism and mathematical modeling of earthquake ionospheric precursors registered in total electron content, Geomagn. Aeron., 49(2), 252-262, doi:10.1134/S0016793209020169.

Ondoh, T. (2003), Anomalous sporadic-E layers observed before M7.2 Hyogo-ken Nanbu earthquake; Terrestrial gas emanation model, Adv. Polar Upper Atmos. Res., 17, 96-108.

Oyama, K.-I., Y. Kakinami, J. Y. Liu, M. A. Abdu, and C. Z. Cheng (2011), Latitudinal distribution of anomalous ion density as a precursor of a large earthquake, J. Geophys. Res., 116, A04319, doi:10.1029/2010JA015948.

Parrot, M., J. J. Berthelier, J. P. Lebreton, J. A. Sauvaud, O. Santolík, and J. Blecki (2006), Examples of unusual ionospheric observations made by the DEMETER satellite over seismic regions, Phys. Chem. Earth, 31, 486-495, doi:10.1016/j.pce.2006.02.011.

Pulinets, S. (2012), Low-latitude atmosphere-ionosphere effects initiated by strong earthquakes preparation process, Int. J. Geophys., 2012, 131842, doi:10.1155/2012/131842.

Pulinets, S., and D. Ouzounov (2011), Lithosphere-atmosphere-ionosphere coupling (LAIC) model-An unified concept for earthquake precursors validation, J. Asian Earth Sci., 41, 371-382, doi:10.1016/j.jseaes.2010.03.005.

Pulinets, S. A., and A. D. Lengen'ka (2002), Dynamics of the nearequatorial ionosphere prior to strong earthquakes, Geomagn. Aeron., 42(2), 227-232.

Pulinets, S. A., V. G. Bondur, M. N. Tsidilina, and M. V. Gaponova (2010), Verification of the concept of seismoionospheric relations under quite heliogeomagnetic conditions, using the Wenchuan (China) earthquake of May 12, 2008, as an example, Geomagn. Aeron., 50(2), 231-242, doi:10.1134/S0016793210020118.

Rhea, S., G. Hayes, A. Villaseñor, K. P. Furlong, A. C. Tarr, and H. M. Benz (2010), Nazca plate and South America: Open-File Rep. 2010-1083-E, 1 map sheet, scale 1:12,000,000, U. S. Geological Survey, Denver, Colo. [Available at http://pubs.usgs.gov/of/2010/1083/e/.]

Rishbeth, H. (1977), Dynamics of the equatorial F-region, J. Atmos. Terr. Phys., 39, 1159-1168, doi:10.1016/0021-9169(77)90024-1.

Rycroft, M. J., R. G. Harrison, K. A. Nicoll, and E. A. Mareev (2008), An overview of Earth's global electric circuit and atmospheric conductivity, Space Sci. Rev., 137, 83-105, doi:10.1007/s11214-008-9368-6.

Ryu, K., E. Lee, J. S. Chae, M. Parrot, and K.-I. Oyama (2014), Multisatellite observations of an intensified equatorial ionization anomaly in relation to the northern Sumatra earthquake of March 2005, J. Geophys. Res. Space Physics, 119, 4767-4785, doi:10.1002/2013JA019685.

Sagawa, E., T. J. Immel, H. U. Frey, and S. B. Mendes (2005), Longitudinal structure of the equatorial anomaly in the nighttime ionosphere observed by IMAGE/FUV, J. Geophys. Res., 110, A11302, doi:10.1029/2004JA010848.

Stolle, C., C. Manoj, H. Lühr, S. Maus, and P. Alken (2008), Estimating the daytime equatorial ionization anomaly strength from electric field proxies, J. Geophys. Res., 113, A09310, doi:10.1029/2007JA012781.

Walia, V., H. S. Virk, T. F. Yang, S. Mahajan, M. Walia, and B. S. Bajwa (2005), Earthquake prediction studies using radon as a precursor in NW Himalayas, India: A case study, Terr. Atmos. Ocean. Sci., 16(4), 775-804.

Walker, G. O., J. H. K. Ma, and E. Golton (1994), The equatorial ionospheric anomaly in electron content from solar minimum to solar maximum for South East Asia, Ann. Geophys., 12, 195-209.

Zhang, X. (2014), Electron density comparison between IRI 2007 and DEMETER satellite data in solar minimum year, Terr. Atmos. Ocean. Sci., 25(4), 559-571, doi:10.3319/TAO.2014.02.24.01(AA).

Zhang, X., X. Shen, J. Liu, X. Ouyang, J. Qian, and S. Zhao (2010), lonospheric perturbations of electron density before the Wenchuan Earthquake, Int. J. Remote Sens., 31(13), 3559-3569, doi:10.1080/01431161003727762.

Zhang, X., X. Shen, J. Liu, Z. Zeren, L. Yao, X. Ouyang, S. Zhao, G. Yuan, and J. Qian (2013), The solar cycle variation of plasma parameters in equatorial and mid latitudinal areas during 2005-2010, Adv. Space Res., 54, 306-319, doi:10.1016/j.asr.2013.09.012.

Zhao, B., M. Wang, T. Yu, W. Wan, J. Lei, L. Liu, and B. Ning (2008), Is an unusual large enhancement of ionospheric electron density linked with the 2008 great Wenchuan earthquake, J. Geophys. Res., 113, A11304, doi:10.1029/2008JA013613. 